\title{
Getting Green with Solar Subsidies: Evidence from the California Solar Initiative
}

\author{
Jonathan E. Hughes ${ }^{1 \dagger}$ and Molly Podolefsky ${ }^{1 *}$
}

January 7, 2015

\begin{abstract}
A variety of subsidies to promote energy efficiency and renewable energy have been adopted by electric utilities, localities, and state governments. We study the California Solar Initiative and find that upfront rebates have a large effect on residential solar installations. We exploit variation in rebate rates across electric utilities over time and control for time-varying factors that affect solar adoption. Our preferred estimates suggest increasing rebates from $\$ 5,600$ to $\$ 6,070$ would increase installations by 10 percent. Overall, we predict 53 percent fewer installations would have occurred without subsidies. Over 20 years, we estimate these additional installations reduce carbon dioxide emissions between 2.3 and 3.4 million metric tons and local air pollutants (NOx) by 1,100 to 1,700 metric tons, about as much as is produced by a small to mid-sized natural gas power plant. Of the $\$ 440$ million in rebates awarded, $\$ 121$ million were rents to installations that would have taken place absent rebates. Back of the envelope calculations suggest program costs of $\$ 0.06$ per kilowatt hour and between $\$ 130$ and $\$ 196$ per metric ton of carbon dioxide.
\end{abstract}

*The authors thank Severin Borenstein, Charles de Bartolome, Brian Cadena, Lucas Davis, Nicholas Flores, Catherine Hausman, Matthew Kahn, Austin Smith and seminar participants at the University of California Energy Institute, the CU Environmental and Resource Economics Workshop, and the $8^{\text {th }}$ Annual International Conference on Environmental, Cultural, Economic and Social Sustainability. Jean Agras of Ventyx and Thomas Dickinson, at CU Boulder generously provided geographic and Census data.

${ }^{1}$ Department of Economics, University of Colorado at Boulder.

$\dagger$ Corresponding author. 


\section{Introduction}

Many state and local governments have become involved in efforts to reduce local air pollution and emissions of greenhouse gases. Electric utilities have also adopted policies to promote residential energy efficiency and renewable energy production. For both groups, a common approach is the use of subsidies for "green technologies." In this paper, we study a popular program that awards rebates for residential photovoltaic (PV) solar electricity installations in California. Currently, over 130 programs in 27 states and the District of Columbia award rebates for residential PV systems 11 If the effects of these programs are large, residential solar subsidies may play an important role in efforts to reduce carbon emissions. However, while a number of green technology subsidy programs have received attention in the empirical literature, the extent to which solar subsidies create new adopters or lower emissions is still largely unknown. Given that these policies are costly to ratepayers, governments or both, whether they achieve their desired environmental goals is an important policy question.

We study the California Solar Initiative (CSI), a large subsidy program that targets residential and commercial consumers of PV and related solar technologies. We focus on the Expected Performance Based Buydown (EPBB) program. The EPBB awards rebates in dollars per Watt based on expected PV system generation capacity. Using installation data from 2007 to 2012, we estimate the relationship between upfront rebates and adoptions. Three investor owned utilities (IOUs) participate in this program: Pacific Gas and Electric (PG\&E), Southern California Edison (SCE) and San Diego Gas and Electric (SDG\&E). Program rebates are substantial and amount to between 5 and 25 percent of system cost. CSI rebate rates decline over time depending on each utility's total installed capacity. This creates variation in rebates across utilities over time that we exploit in our empirical analysis.

Our approach is reduced form. We estimate the static relationship between rebate levels and adoption by flexibly controlling for consumer and market characteristics that vary over time. Because rebate levels depend on the history of past installations and unobserved factors that affect adoption may be correlated over time, our estimation strategy controls for utility-specific timevarying factors related to PV adoption. Though we abstract from the details of market structure and demand, we use our reduced form estimates to construct cost-effectiveness measures useful in

\footnotetext{
${ }^{1}$ For a current count of residential solar rebate programs see http://www.dsireusa.org/solar/.
} 
evaluating the CSI.

Overall, we find CSI rebates have a large effect on residential PV adoption. Across a number of specifications we find that a $\$ 0.10$ per Watt or 7 percent increase in the mean rebate rate increases the number of installations per day between 7 and 15 percent. In our preferred specification, increasing rebates from $\$ 5,600$ to $\$ 6,070$ would increase installations by 10 percent. Furthermore, while consumers do appear to anticipate changes in the rebate rate by increasing adoptions in the weeks immediately prior to a rebate change, the overall effect we estimate does not depend on this short-run behavior. The estimated effect of the rebate does not differ substantially across the geographic areas we study or across IOUs. We also provide evidence that the level effect of rebates on adoptions is greater later in the sample despite smaller rebates.

To investigate the overall impacts of the CSI we use our estimates to predict the number of installations, solar electricity generation and emissions reductions created by the program. Of the approximately 99,000 installations that occurred over this period, we find nearly 53,000 or 53 percent of installations were due to rebates. This suggests the CSI had a substantial effect on adoptions. The estimated increase in solar generation capacity, approximately $240 \mathrm{MW}$, is small at less than 1 percent of typical electricity load in the state 2 We predict the additional solar generation under the CSI lowers $\mathrm{CO}_{2}$ emissions by 2.3 to 3.4 million metric tons (MMT) and cuts emissions of nitrogen oxides (NOx) by 1,100 to 1,700 tons over 20 years. Program cost, calculated as the average subsidy per unit of electricity generation or carbon abatement, is useful for comparing the CSI to other energy efficiency programs. Based on total rebates paid from 2007 to 2012 of $\$ 440$ million, we estimate program costs of $\$ 0.06$ per kilowatt hour and between $\$ 130$ and $\$ 196$ per metric ton of carbon dioxide. Of the $\$ 440$ million in rebates awarded, approximately $\$ 121$ million were rents to installations that would have taken place absent rebates, which may explain the program's popularity.

Understanding the relationship between PV subsidies and adoptions is important for several reasons. Upfront rebates of the type awarded under the CSI are widely used. Programs similar to California's have been used by many utilities, state and local governments $3^{3}$ In addition to

\footnotetext{
${ }^{2}$ Daytime loads in California typically range between 25,000 and 30,000 MW but can peak as high as 60,000 MW.

${ }^{3}$ Examples of other statewide PV incentive programs include Oregon's Solar Electric Incentive Program, New York state's PV Incentive Program and Massachusetts' Commonwealth Solar II Rebate Program. Details on these and similar state administered PV cash subsidy programs are available at DSIRE, the Database of State Incentives for Renewables \& Efficiency, sponsored by the US Department of Energy, http://www.dsireusa.org
} 
upfront rebates, tax rebates and production based subsidies may provide similar incentives. The US federal government has awarded a tax rebate of up to 30 percent for qualified solar installations since 2005. Internationally, several nations including Germany and Spain, offer production based subsidies. Recent work by Burr (2012) suggests consumers may respond similarly to these different incentives. Understanding how consumers respond to incentives highlights the costs and benefits of promoting PV adoption and may help policy makers design more effective policies. Finally, understanding the effects of solar subsidies provides insight into similar programs for other green energy technologies.

This paper is part of a small but growing literature to understand the impact of subsidies for solar PV. Bollinger and Gillingham (2012) explore the role of CSI rebates in their study of peer effects in PV adoption. They use 33 zip codes along the PG\&E and SCE boundary to show that higher CSI rebates are associated with higher adoption rates.4 In contrast to Bollinger and Gillingham (2012) who use indicator variables for rebate changes, we use the actual rebate levels to quantify the relationship between rebate rates and the number of adoptions. More recently, Burr (2012) explores consumer responses to different incentive designs in the context of the CSI. Using a dynamic structural model for consumer utility she finds adoptions would be 85 percent lower in the absence of current CSI subsidies. She finds the CSI would be welfare neutral for a social cost of carbon of approximately $\$ 100$ per MT. Burr assumes that variation in rebate rates is exogenous, an assumption we explore in our work.

In addition, a number of authors have explored the effect of subsidies on adoption of other durable green goods. Boomhower and Davis (2014) examine the issue of free riders in the context of a Mexican subsidy program to incentivize adoption of efficient air conditioners. They find that while the program did encourage adoption, a large percentage of households would have purchased air conditioners in the absence of subsidies. Chandra, Gulati, and Kandlikar (2010) investigate the effect of tax rebates on hybrid vehicle adoption and find a large share of hybrid vehicle adoptions, approximately 74 percent, would have occurred without incentives. These results are consistent with our finding that 47 percent of households who adopted PV under the CSI would have adopted without rebates.

Several authors have investigated the effects of a variety of demand side incentives for hybrid

\footnotetext{
${ }^{4}$ Specifically, they focus on periods when the rebate on one side of the boundary is higher than the other. However, they only consider two rebate changes.
} 
vehicle adoption. Gallagher and Muehlegger (2011) study consumer responses to different types of incentives, and find the type of incentive matters as much as its magnitude. They find the effect of sales tax waivers on adoption to be ten times that of income tax credits, in part due to their relative immediacy and simplicity. Beresteanu and Li (2011) study the effects of federal tax incentives on hybrid vehicle sales. They find 20 percent of hybrid vehicle sales in their sample are the result of tax credits. Sallee (2011) investigates the incidence of tax credits for the Toyota Prius, and finds consumers fully capture these incentives. Finally, Mian and Suf (2012) study subsidies for adoption of fuel efficient vehicles in the "Cash for Clunkers" program. Both Sallee (2011) and Mian and Sufi (2012) provide evidence that consumers adjust the timing of automobile purchases in response to incentives, behavior similar to the short-run effects we observe in the CSI.

This paper also contributes to a larger literature on the costs and benefits of solar. Borenstein (2008) estimates benefits of PV due to generation coinciding with peak demand, and reduced congestion of transmission and distribution systems. Baker et al. (2013) focus on the importance of different time horizons and associated goals in determining the cost effectiveness of solar PV. Van Benthem, Gillingham, and Sweeney (2008) investigate whether PV subsidies are justified through decreases in balance-of-system (BOS) costs via learning-by-doing, and Dastrup et al. (2012) investigate the extent to which PV installations are capitalized into house values. Recent work by Gowrisankaran, Reynolds, and Samano (2013) focuses on the social cost of intermittent solar production in large-scale electricity generation. We focus on the effectiveness of a specific policy to promote solar electricity in California and estimate costs and benefits of this program.

Finally, there is growing interest in the "greenness of cities" (Glaeser and Kahn, 2010) in general, and in programs promoting energy efficiency in residential and commercial buildings. Recent evidence suggests residential and commercial buildings certified as sustainable or energy efficient by "green labeling" programs sell or lease for higher prices relative to comparable uncertified buildings (Deng, Li, and Quigley, 2012; Eichholtz, Kok, and Quigley, 2013; Kahn and Kok, 2013). The effects of these programs appear correlated with local environmental preferences and climate Kahn and Kok, 2013). Millard-Ball (2012) studies the impacts of "city climate plans" on outcomes including bicycle and pedestrian facilities, green buildings and solar adoption. Cities with climate plans are more likely to invest in green technologies. However, this appears to be the result of underlying environmental preferences in these areas rather than the plans themselves. These results highlight the spatial aspects of demand for energy efficient building technologies that may parallel trends in 
solar adoption.

The remainder of this paper is organized as follows. Section 2 describes the California Solar Initiative. Section 3 discusses demand for residential PV. Section 4 presents our empirical strategy and Section 5 describes our data. Sections 6 and 7 summarize our main empirical results and calculations for the overall effects of the CSI. Finally, Section 8 concludes.

\section{Policy background}

The California Public Utilities Commission (CPUC) created the California Solar Initiative (CSI) at the start of 2007 to manage the state PV rebate program and to help meet the solar goals set by the California greenhouse gas law, AB32. The CSI is a $\$ 2$ billion program targeting both commercial and residential customers and includes incentives aimed at low income households in single and multi-family residences. The CSI is funded by a ratepayer surcharge assessed by utilities ${ }^{5}$ This surcharge contributes an average of $\$ 217$ million annually to the CSI ${ }^{6}$ Three IOUs participate in the initiative-Pacific Gas and Electric (PG\&E), Southern California Edison (SCE) and San Diego Gas and Electric (SDG\&E). Rebates are available for solar PV technologies as well as solar hot water heaters. In addition, the CSI offers grants for research, development and deployment of solar technologies. We focus on incentives for residential solar PV installations that represent approximately $\$ 500$ million of the overall program budget 7 For these customers the CSI program offers two options, an upfront rebate based on predicted system electricity production, and a monthly payment based on actual production. Because relatively few customers select the monthly option, we focus on the upfront payment called the Expected Performance Based Buydown $(\mathrm{EPBB}) \cdot 8$

Under the EPBB system, rebate rates begin at $\$ 2.50$ per Watt and decrease based on each IOU's total installed solar capacity. The schedule, reproduced in Table 1, was set at the program outset and allocates the statewide solar capacity to utility-specific quantities within each rebate "step."

\footnotetext{
${ }^{5}$ The surcharge is collected as part of an existing distribution surcharge. Unfortunately, this makes it difficult to observe the actual CSI fee.

${ }^{6}$ This and other surcharges are detailed in a CPUC (2006) ruling clarifying responsibilities of the IOUs in complying with California Senate Bill SB1.

${ }^{7}$ In CSI documents this program is sometimes referred to as the "general market program."

${ }^{8}$ Fewer than 1 percent of residential installations in our sample opted for the monthly PBI payment.
} 
For example, for statewide PV capacity greater than $50 \mathrm{MW}$ and less than $70 \mathrm{MW}$, CSI rebates are awarded at step 2 or $\$ 2.50$ per Watt. However, determining whether a particular residential installation in an IOU qualifies for the step 2 incentive requires that the program administrator allocate the total capacity within the step to the different utilities and their residential and commercial customers. Table 1 shows PG\&E residential installations that occur when the utility's total residential PV capacity is less than $10.1 \mathrm{MW}$ receive $\$ 2.50$ per Watt. Similarly for SCE and SDG\&E, the relevant thresholds are 10.6 and 2.4 MW. The remaining capacity within the step is allocated to commercial installations under each of the participating IOUs. Looking ahead to the empirical exercises, we exploit the fact that rebate levels change at different times for each IOU depending on that utility's installed residential capacity.

Overall, CSI statistics suggest the program had a large effect. As of February 2013, CSI reports 1,432 MW of capacity installed or pending under the program consisting of nearly 142,000 projects. Approximately $546 \mathrm{MW}$ are listed as residential with the remaining $886 \mathrm{MW}$ classified as commercial. Since 2007 , over $\$ 1.5$ billion in incentives have been awarded including over $\$ 400$ million for residential installations.

In addition to the CSI, two other features of the solar market during this period are worth noting. First, during our sample the federal government offered a tax credit of up to 30 percent of system cost for homeowners who installed PV. The credit was initially capped at $\$ 2,000$. However, the cap was removed after December 31, 2008 as part of the American Recovery and Reinvestment Act. Since the mean installation cost in our sample is approximately $\$ 40,000$, removal of the cap greatly increased the size of the federal incentive. Second, the end of our sample saw a dramatic increase in residential PV systems owned by third-parties 9 In these cases, the PV equipment is owned by a firm who then either leases the system back to the homeowner or who sells the residence electricity via a power purchase agreement. This business model may be attractive to capital or credit constrained households and may increase the pool of potential solar adopters. Because these changes may affect PV adoption rates over time, our empirical model below captures these and other time-varying factors using time fixed-effects 10 The increase in third-party PV providers also has important implications for the interpretation of our results. If for example there is incomplete pass

\footnotetext{
${ }^{9}$ Based on our calculations in 2007 approximately 7 percent of CSI installations were owned by third parties. However, by 2011 approximately 53 percent were third-party owned.

${ }^{10}$ These factors may also change the effect of rebates on adoption. We explore this possibility by estimating the effect of rebates in different time periods. These results are shown in Table 7 below.
} 
through of CSI rebates to customer leases or power purchase agreements, the effects we measure later in the sample may increasingly reflect the behavior of PV providers instead of consumers.

\section{Demand for residential solar}

We estimate the reduced form relationship between CSI rebates and PV installations in California. Understanding this relationship sheds light on the level of incentives needed to meet policy goals such as the number of new installations, solar electricity generation capacity and carbon emissions reductions. We can also use our estimates to calculate cost effectiveness measures useful for evaluating the CSI. We employ a reduced form approach in part because we are limited to zip code level data on installations and prices. In addition, abstracting from the details of market structure and demand simplifies our empirical task while still providing useful information about PV adoption. The disadvantage of this approach is that without an estimate of demand and an understanding of competition, we are unable to investigate the full welfare implications of the CSI.

To understand our estimation strategy, we first discuss key aspects of residential solar demand 11 To begin, consider a fixed number of potential solar adopters ${ }^{12}$ Each potential adopter weighs PV system price, the rebate amount, and expected electricity savings. Households may also get flow utility from a PV installation, for example due to pro-environmental preferences, e.g. warm glow. Because rooftop PV systems have a lifetime of approximately 20 years, benefits from flow utility and electricity savings accrue over many years. Therefore, we assume potential adopters install solar if the present discounted value of future consumption, both electricity savings and warm glow, exceeds the system price net of the CSI rebate.

This simple model raises several important issues for our estimation. Imagine households perfectly predict their future preferences and prices. Because CSI rebates decline over time, this implies all adoptions will occur during the first period when CSI rebates are highest, and will be zero thereafter 13 However, as we will see in Section 5, the number of adoptions per day increases steadily over time despite falling rebates. Possible explanations for this result are that net prices

\footnotetext{
${ }^{11}$ Section 4 presents the details of our empirical model.

${ }^{12}$ While in principle new potential adopters could arrive over time, for example due to population growth, we assume this effect is small. Over the period we study, California population increased less than $4 \%$.

${ }^{13}$ Alternatively, fixed prices and preferences would lead to a similar result.
} 
are decreasing, electricity expenditures are increasing or environmental preferences are growing over time. If household expectations are based on current prices and preferences, adoptions could increase over time despite falling rebates. For example, consider a two period model with net PV prices $P_{1}$ and $P_{2}$. In period 1 consumers with willingness to pay greater than $P_{1}$ install solar. Because rooftop PV systems are durables these households effectively exit the market. However, this does not necessarily imply zero installations will occur in period 2. Holding demand fixed, new households will adopt in the second period if net price $P_{2}$ is less than $P_{1}{ }^{14}$ This could occur, for instance, if system prices fall faster than rebates. Similarly, consider an increase in solar preferences from period 1 to period 215 Holding system price fixed, a sufficiently large increase in preferences leads to additional installations in period 2.

Against this background of shifting adoption patterns, we are interested in how changes in rebates affect installations all else equal. Fortunately for our purposes, the CSI program creates variation in rebates across utilities and within utilities over time. Therefore, by looking at installations within a utility before and after rebate changes and across utilities that offer different rebates at a given time, we can recover the relationship between rebates and adoptions. Our estimate is a reduced form effect because we abstract from the details of competition and demand that determine how rebate changes relate to PV system prices. Further, we assume households' expectations about future prices and preferences are based on current prices and preferences ${ }^{16}$ This assumption has the advantage of reducing a complex dynamic PV adoption problem to a simpler static problem that depends on current rebates, prices and preferences. While this assumption greatly simplifies our empirical task, it requires that we account for time-varying factors that affect PV adoption. We do this by combining time fixed effects with the geographic discontinuity created by utility territory boundaries. We assume that within any time period, the time fixed effects hold system prices and solar preferences constant. We discuss the details of our empirical model in the following section.

Our approach raises two additional concerns. First unless demand is linear, changes in prices or solar preferences may also affect the marginal relationship between rebates and adoptions. We

\footnotetext{
${ }^{14}$ If changes in prices or preferences occur slowly we would expect the market for solar to quickly become saturated. However, the fact our data below show strong increases in adoption rates over time suggests saturation effects may be small during our sample. Section 6.3 presents additional evidence against strong saturation effects.

${ }^{15}$ For example, changing environmental preferences or increased familiarity with PV technology that increases willingness to pay.

${ }^{16}$ There is support for this assumption in other energy markets. For example, Anderson, Kellogg, and Sallee (2013) provide evidence that, on average, consumers expect the future real price of gasoline to equal the current price.
} 
explore this issue by investigating whether our estimates vary by utility, geography or time period in Section 6.2. Second, the declining schedule of CSI rebates creates the possibility of short-run dynamics if potential adopters anticipate rebate changes. Specifically, households may rush to install in order to take advantage of higher rebate levels prior to a rebate change. Therefore, adoption behavior may include both a short-run dynamic component due to rebate changes and a static effect due to lower net system prices. This combination of behaviors does not seem unreasonable. For example, one model consistent with this behavior is rational inattention. Once solar prices, rebates, electricity prices and preferences make a consumer at risk of adopting solar they seek out the best deal. Here, getting the best deal may mean moving up the installation by a few weeks to take advantage of higher rebates. However, for most policy questions one would not want to include this short-run behavior in estimates of the effect of rebates on adoption.

In Section 4 we describe our empirical approach and how we attempt to identify the static relationship between rebates and adoptions. In Section 6, we present a variety of robustness checks to demonstrate that our estimates are not overly sensitive to the base model described below.

\section{Empirical strategy}

The first identification challenge comes from the fact that preferences for solar PV systems may be changing over time. This problem presents itself in two ways. First, stronger environmental preferences or increased familiarity with solar may mean a lower rebate is required to cause adoption. Second, although changes in rebate levels follow a predetermined formula set by the CSI, the exact timing of changes depends on the number of prior installations. Because unobserved factors that affect adoptions within each utility territory may be correlated over time, one may worry that rebate levels are endogenous. Therefore, our identification strategy seeks to isolate exogenous variation in rebate rates while holding constant unobserved factors that affect PV adoption. ${ }^{17}$

We combine two strategies in our primary specification. First, we use time fixed effects to account for mean and utility specific time varying unobservables that affect PV adoption. Second, we exploit the geographic discontinuity created by the boundary between the PG\&E and SCE

\footnotetext{
${ }^{17}$ For example, environmental preferences may vary over time. Bollinger and Gillingham $(2012)$ show hybrid vehicle registrations, a proxy for environmental preferences, are positively correlated with PV adoption. Millard-Ball (2012) shows observable and unobservable local characteristics likely play a role in PV adoption decisions. Our identification strategy assumes solar preferences at any given point in time are similar on each side of the utility boundary.
} 
service territories. This boundary was created in the early 1900's when the area between the two utilities was largely rural, such that the location is plausibly orthogonal to factors affecting PV adoption today. We focus on a narrow 20 mile corridor around this territory boundary. This approach is similar to Bollinger and Gillingham (2012) who use the border between PG\&E and SCE to study the effects of changes in PV rebates on installations and Ito (2014) who investigates consumer responses to marginal and average electricity prices using the territory boundary between SCE and SDG\&E in Southern California. Because changes in the rebate rate are determined by total installed PV capacity in either IOU's territory, installations in the boundary region should minimally affect the rebate rate. Further, by looking in a small neighborhood around the boundary we hope to hold constant unobserved factors affecting adoption. A key identifying assumption is unobservables that affect adoption for households in the boundary region are not correlated with unobservables at the utility level more broadly.

To get a sense for the similarity of households within each region, Table 2 summarizes zip code mean demographic and housing characteristics for all zip codes within the PG\&E and SCE territories as well as within 40-mile and 20-mile wide corridors at the territory boundary. These observable characteristics are reasonably good predictors of PV installations 18 We present means weighted by population within each zip code. Beginning with the full sample, we see percent white, household income, percent family occupied, and number of rooms are all significantly different between PG\&E and SCE territories 19 When the sample is limited to the 40-mile corridor around the boundary, the differences in observable characteristics between utilities in general decrease. Income and number of rooms are no longer statistically significantly different. Finally, moving to the preferred 20-mile corridor sample, we see that the differences decrease further. In no case are the differences in means between utilities significant at the 5 percent level and only in the cases of percent white and percent family occupied are they significant at the 10 percent level. This suggests focusing on a small neighborhood around the utility boundary does result in observations with similar observable characteristics. Furthermore, unobservables that affect solar installations may be correlated with these observable factors. These results suggest the 20-mile corridor sample

\footnotetext{
${ }^{18}$ A regression of total PG\&E and SCE installations from 2007 through 2012 by zip code on the variables in Table 2 explains approximately 46 percent of the variation in adoptions. The observable characteristics are jointly significant $F(7,1087)=135.94$ and each variable is independently statistically significant $(p<0.01)$ with the exception of percent of units that are owner occupied.

${ }^{19}$ Number of rooms can be thought of as a proxy for house size.
} 
may also hold these factors constant across utilities 20

Next is the issue of electricity prices. While our model includes utility by year mean effects, electricity rates may change within a year affecting the demand for solar. Therefore, we control for electricity prices directly using each IOU's rates for the three highest tiers. Because the upper rate tiers charge higher prices for households with higher monthly consumption, we view price changes in the top three tiers as being the most important predictors of PV adoption 21 We estimate our base specification using zip code level data where we sum installations to produce daily installation totals for each zip code. Where zip codes are divided by the utility boundary, we sum installations separately be IOU within the zip code. Because zip codes have substantially different populations, we must account for how differences in population affect adoption. We divide daily installations by each zip code's population to construct a per capita daily installation rate. Since our Poisson and negative binomial regressions imply i.e. $\frac{\text { Installs }_{i, t}}{\text { Pop }_{i}}=\exp \left(X_{u, t} \beta\right)$, we generalize the per capita model by using daily installations as our dependent variable and including log population as an explanatory variable.

Under these assumptions we estimate:

$$
I_{i t}=\beta_{0}+\beta_{1} \text { rebate }_{u t}+\beta_{2} \ln \left(\text { pop }_{i}\right)+\beta_{3} \text { tier } 3_{u t}+\beta_{4} t i e r 4_{u t}+\beta_{5} t i e r 5_{u t}+\epsilon_{u y}+\epsilon_{i t}
$$

Where $I_{i t}$ is a count variable for the daily installation rate for zip code $i$ at time $t 22$ Since the rebate rate determines the net cost to the consumer of adopting solar, rebate $u t$ the rebate offered by utility $u$ at time $t$ enters in levels. $\ln \left(\right.$ pop $\left._{i}\right)$ is the natural $\log$ of population for zip code $i$. Because unobserved time varying factors such as marketing programs, third-party installers, changes in familiarity with PV technology and peer effects may also vary by utility, our preferred specification also includes utility by year mean effects $\epsilon_{u y}$. This also captures time varying factors common to both utilities, such as changes in the federal tax code and PV component prices. We exclude PV system prices for two reasons. First, prices reported to the CSI may be unreliable because

\footnotetext{
${ }^{20}$ While these results also suggest a more narrow corridor may be desirable, we do not observe the precise installation location. Therefore, the fineness of the discontinuity is limited by the width of each zip code, which can be several miles.

${ }^{21}$ We thank an anonymous referee for this suggestion.

${ }^{22}$ For our OLS model $I_{i t}$ is the per capita installation rate for zip code $i$ at time $t$ and the estimating equation is $I_{i t}=\beta_{0}+\beta_{1}$ rebate $_{u t}+\beta_{2}$ tier $3_{u t}+\beta_{3}$ tier $4_{u t}+\beta_{4} t i e r 5_{u t}+\epsilon_{u y}+\epsilon_{i t}$.
} 
of incentives for third-party installers to over-report costs.23 Second rebate levels, rather than consumer prices net of rebates, may be more salient for policy makers 24

The final issue relates to the possibility that potential adopters anticipate rebate changes and rush to adopt in the weeks prior to a rebate change. The strategy we take in dealing with this issue is to exclude observations near the rebate changes. This is similar to the "Donut-RD" approach outlined by Barreca, Lindo, and Waddell (2011) for addressing heaping in a regression discontinuity framework. In our preferred results we drop observations four weeks before and four weeks after each rebate change. In Section 6 we present robustness checks using different windows. Implicitly, we are assuming any dynamic shifting of adoptions occurs during the excluded period and the remaining adoptions reflect the static response to rebates. This approach seems reasonable since the moving up of installations is likely to be relatively short-run in nature for two reasons. First, the timing of rebate changes is fairly uncertain and the uncertainty grows the further one must forecast into the future. Recall rebates depend on total installed PV capacity within each IOU. Second, PV prices are falling fairly rapidly over this period, which means there is option value in waiting to install.

We estimate the parameters of Equation 1 using negative binomial regression. Given count data and the potential for a large fraction of zero values, the negative binomial model seems a reasonable choice. We test for overdispersion using the regression based test proposed by Cameron and Trivedi (2005). We reject the null hypothesis of no overdispersion with $t=5.51(g(\mu)=\mu)$ and $t=6.10\left(g(\mu)=\mu^{2}\right)$. In light of these results, we adopt the negative binomial as our preferred specification but also present results of $O L S$ and Poisson specifications for comparison.

\section{Data}

Our analysis exploits installation data from the California Solar Initiative (CSI). CSI reports installation date, rebate amount, utility and zip code as well as installation characteristics for all

\footnotetext{
${ }^{23}$ Installers may receive a federal tax credit under the Investment Tax Credit program based the fair-market value of leased systems. This may lead to misreporting of prices as alleged by the US Treasury. http://www.renewableenergyworld.com/rea/news/article/2012/10/treasury-dept-fingers-solarcity-inexploration-of-the-dark-underbelly-of-solar-leasing.

${ }^{24}$ Of course, the effect of rebates on consumer prices requires an understanding of subsidy pass-through from installers to consumers, which may vary from market to market. Here by focusing on the reduced form effect of rebates, we implicitly lump pass-through into an overall effect of changing rebate levels on adoption.
} 
solar PV systems that received an incentive under the program 25 We focus on the period from the beginning of the program on January 1, 2007 through October 31, 2012. We use only installations that received the upfront EPBB payment and exclude installations that opted for the monthly PBI incentive. The CSI data include all projects for which an application for a rebate was submitted regardless of whether the project was completed. We drop all observations for cancelled or delisted projects. We use only those installations classified as residential by CSI. The CSI data lists dates of several important project milestones. We use the date of the "first reservation request review" as the date for each project. The reservation request date is the date at which a customer first applies for CSI funds. It establishes a contract between the system owner and the CSI whereby the customer is guaranteed the CSI rebate rate at the time of the reservation request. Since the actual installation date depends on permitting, construction and installation timing, we view the reservation request date as the best approximation of the customers actual decision date ${ }^{26}$ Finally, CSI lists the actual rebate rates as well as the total incentive amount awarded to each project. However, many of the actual rebates listed are constructed as weighted averages of two steps 27 To minimize the potential for bias if strategic customers are able to obtain higher effective rates when weighted average rates are used, our calculations use the CSI reported incentive step and rebate rate corresponding to the reservation request date for each project instead of the reported weighted average ${ }^{28}$ The correlation coefficient between our measure of the rebate rate and the rate reported for each project is 0.99 .

Table 3 presents summary statistics for the total rebate awarded, system cost and size by utility. The CSI rating is the electricity generation capacity adjusted for installation specific parameters such as inverter efficiency, panel orientation, and the solar energy resource of the installation location. Looking across IOUs, average system prices range from approximately $\$ 35,900$ to $\$ 37,400$

\footnotetext{
${ }^{25}$ We use the "Working Data Set" file posted on November 14, 2012. We drop the last two weeks to account for any lag in updating the CSI database with new installations.

${ }^{26}$ Upon approval of the reservation request, customers are allowed 12 months to install the specified PV system. In our sample, approximately 10 percent of reservations are suspended or cancelled. In light of this, some households may view the reservation request as an option to install PV at the current rebate rate. Since we exclude cancelled projects, the reservation request date captures the timing of the PV decision, conditional on adoption.

${ }^{27}$ Presumably this is due to some feature of the timing of application and installation of the various projects that may have occurred around a rebate change date.

${ }^{28}$ We observe the dates at which rebate levels for the IOUs changed from CSI press releases, annual reports and the "Go Solar California" monthly newsletter. While rebate change dates were not pre-announced, consumers and installers were provided information about the remaining capacity at each rebate level (step) via a web-based "CSI Trigger Tracker" application.
} 
and rebate levels range from $\$ 3,600$ to $\$ 5,300$ in nominal dollars. Average CSI ratings are fairly consistent at between 4.46 to $4.77 \mathrm{~kW}$ The data also suggest large subsidies are awarded for a few very large residential installations. Across the three IOUs, maximum rebates range from $\$ 106,000$ to $\$ 138,000$ for systems costing between $\$ 397,000$ and over $\$ 1$ million.

In the empirical specifications below we focus initially on a subsample defined by a 20-mile corridor around the boundary between PG\&E and SCE. In this sample, shown in the bottom panel of Table 3, rebates and system sizes are somewhat larger relative to the full sample. The total number of installations per day for PG\&E and SCE average from 16.4 to 23.4 in the full sample and from 0.56 to 0.85 per day in the 20-mile corridor. In the full sample of zip codes approximately 22 percent of daily observations have no installations compared with 63 percent of zip code level observations in the 20-mile corridor. Finally, our base specifications below use zip code level installation data. Here, zip code level installation rates are quite low, between 0.01 and 0.03 per day on average.

Next, we consider the location of installations under the CSI. Figure 1 shows the total number of residential PV installations under the CSI by zip code divided by zip code level population density. Solar intensity is higher outside major cities. For example, there are relatively few installations per capita in the most densely populated parts of the San Francisco and Los Angeles metro areas. Instead, solar intensity is highest in a ring of zip codes outside each city. This likely reflects our focus on residential installations, which are more likely to occur on single family homes. This pattern illustrates the CSI may contribute to the "greenness" of a cities' housing stock, outside of the urban core. Since Glaeser and Kahn (2010) find that in general, $\mathrm{CO}_{2}$ emissions from electricity consumption are larger for suburban than for urban households, this pattern of adoption may magnify the effect of solar rebates on emissions 30

To illustrate the overall trends in rebates and installations, Figures 2(a), 2(b) and 2(c) summarize average rebate rates, system prices and installations for PG\&E, SCE and SDG\&E from 2007 through 2012. Rebate levels begin at $\$ 2.50$ per Watt in 2007 and decrease to $\$ 0.20$ per Watt for PG\&E and SDG\&E, and $\$ 0.25$ per Watt for SCE by 2012. Notice the rebate steps change at different times for each utility. This is the main source of variation we exploit in our empirical

\footnotetext{
${ }^{29}$ In our CSI data there are 51 installations larger than $30 \mathrm{~kW}$ that received the EPBB rebate instead of the PBI. Excluding these observations from the sample does not affect the results reported below. In addition, there are 11 instances of system prices reported as zero. Excluding these observations does not affect our results.

${ }^{30}$ In California, Glaeser and Kahn (2010) find this is true in San Francisco and Sacramento, but not Los Angeles.
} 
analysis. Average system costs per Watt decrease over the period from approximately $\$ 10$ per Watt to $\$ 6$ per Watt. Average daily installations increase from nearly zero, initially, to almost 50 per day in 2012 for PG\&E and SCE. Daily installations are substantially lower for SDG\&E, peaking at approximately 15 per day 31 Given that prices have steadily decreased over time while installation rates have risen, one may wonder about the impact of CSI rebates on adoptions.

Figures 3(a), 3(b) and 3(c) provide evidence consumers do respond to changes in rebate levels. The number of installations per day is plotted for each utility from 2007 through 2012. For exposition we plot only weekdays, though a surprising number of installations are recorded on weekends 32 The vertical lines denote dates when the rebate rate was lowered. In general, we see large increases in the number of installations in the weeks leading up to a drop in the rebate rate. The periods between rebate changes also show a general upward trend consistent with greater numbers of installations over time. Looking forward to the empirical exercises, the overall increase in installation rates combined with decreasing rebate levels suggests controlling for changes in time-varying factors that affect PV adoption will be important in identifying the effect of rebates on installations.

Our empirical model controls for changes in electricity prices over time and differences in population across zip codes. For electricity prices we collect rates for the three highest consumption tiers from the historical tariffs of each IOU. Electricity rates are in nominal dollars. Results using rebates and electricity prices adjusted for inflation yield very similar results. For population we use zip code totals from the 2000 Census. Where the utility boundary divides a zip code we assume population is evenly split between IOUs. In several specifications we also use median household and house characteristics from the 2000 Census. We observe population for approximately 83 percent of CSI installations. We exclude zip codes with missing data from our initial analysis. However, we show in Table 8 that the estimated effect of rebates is very similar when population is excluded and all installations are used.

Finally, our base model uses the boundary between the PG\&E and SCE territories to help create exogenous variation in CSI rebate rates. We focus on PG\&E and SCE because SDG\&E represents a substantially smaller share of adoptions. We use GIS data from Ventyx to locate the

\footnotetext{
${ }^{31}$ This difference may largely be due to the relative sizes of these utilities. While SCE and PG\&E serve 14 and 15 million electricity consumers respectively, SDG\&E serves only 1.4 million. In per capita terms, 2012 installations are significantly higher in SDG\&E than in either SCE or PG\&E.

${ }^{32}$ Our estimates for the effect of rebates on adoption in Section 6 include installations on weekdays and weekends. Parameter estimates are similar to those reported when weekends are excluded.
} 
boundary and to identify zip codes that lie within a 20 -mile corridor around the boundary. Figure 4 shows the PG\&E and SCE service territories as well as the region around the territory boundary. These two IOUs serve regions that cover the vast majority of the state stretching from southern California to near the Oregon border. The boundary between PG\&E and SCE, drawn in black, begins in Santa Barbara and stretches nearly 900 miles north to the Nevada border. Zip codes whose centroids fall within the 20-mile corridor are shaded in gray. Because less populous zip codes tend to be larger in size, the 20-mile corridor excludes some rural regions of the boundary as some zips code centroids do not fall within 10 miles of either side of the territory boundary 33

\section{The effect of rebates on solar panel adoption}

\subsection{Installations along the PG\&E and SCE boundary}

We begin by focusing on installations near the PG\&E and SCE boundary. Table 4 presents estimates of the effect of the rebate rate on PV installations under different specifications of Equation 1 in the 20-mile corridor sample. Column 1 reports results of the OLS model, column 2 and column 3 show results estimated with Poisson and negative binomial regression, respectively. We report standard errors clustered at the utility level to allow for the possibility of serial correlation and correlations in errors across zip codes. Column 3 is our preferred model ${ }^{34}$ Focusing on the negative binomial results, the coefficient on the rebate rate is 0.963 and is statistically significant $(p<0.05)$. At the mean rebate level of $\$ 1.46$ per Watt, this estimate implies an increase of $\$ 0.10$ in the rebate rate corresponds to a 10.1 percent increase in the daily installation rate. The coefficients on tier 3 and tier 5 electricity prices are positive and statistically significant as expected. The coefficient on tier 4 prices is negative and not statistically significant. This is likely due to collinearity of tier 4 and tier 5 prices later in the sample. The estimated coefficient on log population is 0.989 and is statistically significant $(p<0.05)$. We fail to reject the hypothesis that population coefficient is one with $p=0.87$. In the Poisson model, the estimated coefficients are quite similar. In the $O L S$ specification, the dependent variable is the daily installation rate per 10,000 persons population. Evaluated at the sample mean, a $\$ 0.10$ per Watt increase in the rebate rate increases the average

\footnotetext{
${ }^{33}$ These zip codes are left unshaded in Figure 4

${ }^{34} \mathrm{~A}$ likelihood ratio test rejects the hypothesis that $\alpha=0$ with a chi-squared statistic of 253.17 , further suggesting the negative binomial model is preferred to Poisson regression.
} 
daily installation rate 19.1 percent. Despite the larger estimated effect, we find the similarity of the OLS results reassuring. However given the discrete nature of the installation data, we adopt a count data model as our preferred specification. All results below are estimated using negative binomial regression.

We investigate the robustness of our estimates to changes in the base model. Table 5 show the results of several alternate specifications. Column 1 reproduces the results of our preferred model. Column 2 imposes common year effects across utilities. Here, the estimated rebate effect is substantially smaller. While our geographic discontinuity approach "holds constant" local unobserved factors affecting PV adoption, it does not control for utility specific trends. For example, utility or installer marketing programs that publicized the CSI program or the benefits of solar, may cause different adoption trends across IOUs 35 This suggests controlling for utility specific time varying factors is important. Next, column 3 excludes electricity prices from the model. Without accounting for rate changes, the estimated effect of rebates is substantially larger. Upper tier electricity prices do appear to play an important role in PV adoption underscoring the need to control for rate changes when estimating the effect of rebates. In column 4 we drop the population control. We see the estimated effect of rebates is very similar to the base model. In some sense this isn't surprising since our negative binomial model already assumes rebate changes lead to proportional changes in installations across zip codes. That said, the similarity of these estimates is reassuring. Finally, the remaining columns present alternate attempts at capturing unobserved spatial factors that affect PV adoption. In column 5 we add zip code level household and dwelling characteristics. Column 6 instead uses zip code fixed effects to model time invariant mean differences across zip codes. Because unobserved factors affecting PV adoption may vary over time, column 7 adds zip code by year mean effects. The estimated effects of rebates on adoptions are quite similar across all three models and are consistent with our base model.

One may be concerned time-varying area-specific factors, such as changing taste for solar, may bias our estimates. The results presented in Table 5 suggest this may not be a major concern. However, one may still be concerned about within-year effects not captured by our model using zip code by year effects. Unfortunately, estimating a model with zip code by year by quarter effects is asking a lot of our data. Within each zip code-year-quarter group in our 20-mile sample, more than

\footnotetext{
${ }^{35}$ Conversations with a senior utility employee suggest marketing strategies did vary substantially by utility and over time.
} 
half of zip codes have zero installations for any date during the quarter. Nearly seventy percent of zip code-year-quarter groups have zero or one installation.

As an alternative, we instead estimate several models using an intermediate level of spatial aggregation but finer time effects. Specifically, we divide the boundary between PG\&E and SCE into eight different geographic regions (zip code groups) by proximity. We then sum up the number of installations per day by utility for zip codes within the eight groups. Aggregation increases the frequency of installations relative to an analysis at the zip code level and allows us to estimate models with zip code group by quarter by year effects. The estimated effects using zip code group by quarter by year effects are quite similar to those in our base model and those using zip code-level data but coarser time effects 36

A second concern relates to our handling of the short-run dynamic behavior around rebate changes, i.e. the rush to sign up. Our base model excludes installations that occur four weeks before and four weeks after each rebate change in an attempt to exclude short-run dynamic effects from our estimates. Table 6 investigates the robustness our our results to changes in the number of excluded weeks. In column 1 we use every week in the sample. In column 2 we drop installations within two weeks of a rebate change. Column 3 shows our base model results excluding installations four weeks before and four weeks after each rebate change. Columns 4 and 5 expand the excluded window to 8 and 12 weeks before and after each rebate change, respectively. We see the estimates in columns 1, 2, 3 and 5 are quite similar. In column 4, the point estimate falls to 0.676 , though statistically we cannot reject that the column 3 and 4 estimates are equivalent. In all cases, the estimated effect of rebates on adoptions is statistically significant. Overall, the relationship between rebates and adoptions seems robust to changes in the excluded period around rebate changes.

\subsection{Time, geographic and utility heterogeneity}

In this subsection we investigate whether the relationship between rebate rates and installations varies over the sample period, by geography or by utility. We begin by looking at different time periods within the CSI program. There are several reasons we might expect the relationship between rebates and adoptions to vary over time. Consumers may respond differently to changes in the rebate rate when the level is relatively high or relatively low. For example, the population

\footnotetext{
${ }^{36}$ These estimates are available from the authors upon request.
} 
of potential adopters may be larger when the overall size of the incentive is greater. On the other hand, the population of potential adopters could be larger later in the sample if environmental preferences grow over time or if there are peer effects. In addition, larger potential federal tax credits after 2008 and the entry of third-party owned systems later in the sample may also change the effect of rebates on a adoption. A closely related issue is the possibility saturation effects. If for example, the population of potential PV adopters is fixed, different IOU installation patterns before the CSI could lead to different rebate effects later.

To investigate these possibilities we divide our sample into three periods from 2007 through 2008, 2009 through 2010, and 2011 through October 2012. Recall from Figures 2(a) and 2(b) average rebate rates drop from period to period, while average daily installation rates increase. To allow for changes in behavior over time, we interact rebate rates with an indicator variable for each two-year period. Table 7 shows the results of this exercise. The point estimates vary from 1.816 early in the sample to 0.745 in the period from 2011 through 2012 . The percentage increase in adoptions due to a $\$ 0.10$ increase in the rebate rate is 19.9 percent in the early period and decreases to approximately 7.7 percent late in the sample. To understand whether this decline is due to a smaller predicted increase in the number of installations or a greater overall daily installation rate we also report the estimated increase in installations in levels. Here, we see a $\$ 0.10$ increase in rebates translates to approximately 0.0019 more installations per day in 2007 and 2008 . In the late period, the effect grows to approximately 0.0027 suggesting the decline in the installation semielasticity is due to higher daily installation rates later in the sample. Overall, these results suggest a relatively larger number of potential solar adopters at the end of the period despite lower rebate levels.

Next we investigate geography. Table 8 presents estimates of the relationship between rebates and daily installation for several different geographic samples. Column 1 includes only zip codes split by the PG\&E and SCE territory boundary. Column 2 is the base sample and includes zip codes within a 20-mile corridor along the boundary. Column 3 expands the boundary to a 40 mile buffer around the territory boundary. Column 4 show results using installations from all zip codes within the PG\&E and SCE territories. Intuitively, allowing more installations away from the boundary increases the likelihood rebate levels are responding to unobserved trends in PV adoption and are therefore endogenous. On the other hand, exploring a larger geographic area can highlight whether the effects estimated in Table 4 are unique to the boundary region or generalize to the 
larger population of PG\&E and SCE ratepayers.

Looking across the different samples, the point estimates are surprisingly similar. This suggests that in percentage terms, the effect of increasing rebates is similar regardless of sample. We interpret this result as evidence that, conditional on controlling for utility specific time varying factors, the geographic discontinuity approach provides little additional benefit in accounting for unobserved factors that affect adoption. This has two implications. First, there may be remaining unobserved factors that do matter, meaning changes in the rebate rate are endogenous. For example, environmental preferences that vary over time but are correlated across each utility's territory. In this case, our estimates of the effect of changes in the rebate can be viewed as lower bounds of the true effect. Second, with the caveat that there may be some remaining bias, the similarity of our estimates across the different samples suggests our results may generalize more broadly to all of PG\&E, SCE and possibly SDG\&E.

In the next section we will analyze the overall effects of the CSI program. To do this we will use daily installations aggregated to the IOU level. Aggregation has two advantages. First, an IOU level model abstracts from zip code level heterogeneity. Because we are missing population data in a subset of zip codes, aggregation allows us to use all installations not just those where we observe zip code-level demographics ${ }^{37}$ Second, the IOU level estimates simplify summing up the overall program effects.

The final two columns of Table 8 present results using total daily installations by IOU as the dependent variable. Column 5 shows the estimated relationship between the aggregate installation rate and rebates is consistent with our zip code level results for PG\&E and SCE. In column 6, we add installations from the third participating IOU San Diego Gas and Electric SDG\&E. These results are also quit similar to the base model. Since the percentage effects are quite similar to those in the various PG\&E and SCE samples, we use the estimates from all three IOUs in our calculations of the overall program effects below.

As a final check we relax our assumption that rebates have the same effect on adoptions across the three IOUs. We estimate the effect of rebate rates on aggregate daily installations by interacting an indicator variable for each utility with the rebate rate. Table 9 summarize the point estimates and the effects associated with a $\$ 0.10$ increase in the rebate rate. We see the effects are very

\footnotetext{
${ }^{37}$ We are reassured by the results in Table 5 that show our results are robust to omitting zip code level population.
} 
similar across IOUs. The estimated impact of a $\$ 0.10$ increase in the rebate rate ranges from a 10.2 percent to 10.8 percent increase in the daily installation rate 38 In our calculations of the overall program impacts below, we adopt the more parsimonious specification assuming equal effects across utilities.

\subsection{Additional evidence on saturation and rebate effects}

Here we consider the role of saturation in the relationship between CSI rebates and installations. Since PV systems have a service life of approximately 20 years, households that adopt exit the market for solar. If certain locations are better suited for solar of if preferences for PV vary substantially, the pool of potential adopters may quickly dry up. On the other hand, PV prices have been steadily falling and the rise of third party PV firms may increase adoptions over time. Therefore, the past history of adoptions may affect adoption in general and the sensitivity to rebates in particular. We provide several additional pieces of evidence against strong saturation effects. We briefly describe this evidence here. Detailed results are available from the authors upon request.

First, we look at a longer trend in PV installations by including data from the Emerging Renewables Program (ERP) that preceded the CSI. Focusing on PG\&E and SCE, both utilities show strongly increasing daily installation rates from 2004 through 2012. Both IOUs exhibit similar time trends, starting with very low installation rates and increasing dramatically over the period. Second, while both IOUs show slight decreases in adoptions for several months around the end of the ERP program in 2007, the overall trends are fairly robust. This suggests external factors such as falling PV prices or growing preferences for solar may be driving overall adoption and underscores the use of time effects in our analysis. Third, since both utilities serve approximately 14 to 15 million customers each, installation rates and installation rates per capita look quite similar for PG\&E and SCE, especially toward the later years of the CSI.

In terms of our empirical results, we note our preferred model includes utility by year effects and therefore captures many utility-specific effects from the ERP that may carry over to the CSI. However, one may still worry that higher (lower) adoption rates under the ERP may make households less (more) sensitive to rebates under the CSI. To investigate this issue we conduct an

\footnotetext{
${ }^{38}$ As an additional robustness check we replicate the service territory border analysis in Table 4 using installations from zip codes within the 20-mile region around the SCE and SDG\&E boundary. A $\$ 0.10$ increase in the rebate rate is associated with a 11.0 percent increase in the daily adoption rate $(p<0.01)$.
} 
analysis similar to that presented in Table 7 allowing the effect of rebates on adoptions to vary by utility by period. We focus on the 20-mile sample around the PG\&E and SCE border. During the ERP, installation rates were about twice as large for SCE compared with PG\&E. Therefore, smaller SCE installation rates under the CSI would be consistent with a large saturation effect. However, we find the opposite result. For SCE the effect of rebates on the number of installations is greater than for PG\&E in all three periods. For both utilities the level effect of rebates on adoptions grows over time consistent with our results in Table 7 .

Finally, we use the CSI data to investigate the characteristics of installations over time. If the "better" locations install PV earlier, rebates may have less of an effect on adoption later in our sample. Therefore, we look to see whether installation characteristics deteriorate over time. We focus on three system parameters in the data, CEC PTC rating, design factor and CSI Rating. The CEC PTC rating measures PV system size taking into account module output under test conditions and inverter efficiency. The design factor is the ratio of a systems expected output to that of a baseline system. In an approximate sense, design factor captures the quality of a particular installation. Finally, the product of CEC PTC rating and the design factor yields the CSI rating, or an estimate of system output. Using installation level data we regress each parameter on utility and year effects. We find design factor falls by approximately 1 percentage point from 2007 to 2012 . Both system size (CEC PTC Rating) and average output (CSI Rating) are larger in 2012 compared with other years, approximately 13 percent and 12 percent. While there is some evidence PV is adopted in better locations initially, this effect appears relatively small. Overall, these results do not seem consistent with large saturation effects.

\section{Overall impacts of the California Solar Initiative}

Given consumer responses to CSI rebates estimated above, we would like to understand the overall effects of the program along several dimensions. Specifically, we are interested in how many installations the CSI generated, what environmental benefits the program conferred and at what cost. We begin by looking at total installations under the CSI. 


\subsection{Installations}

To predict the total number of installations under the CSI program we use the parameter estimates from the sample including all three IOUs, i.e. column 6 of Table 8 . We then compare the predicted number of installations with a counterfactual prediction assuming no rebates. In each case, we generate the predicted number of installations (i.e. $\left.\hat{I}_{u, t}=\exp \left(X_{u, t} \beta\right)\right)$ assuming either the actual CSI rebate or zero rebate then sum over all utilities and all prior periods to calculate the total number of installations to date. Figure 5 shows the results of this exercise where cumulative installations are plotted over time for actual installations, predicted installations under the CSI rebate levels and predicted installations without rebates. Predicted installations follow the actual CSI installations quite closely, beginning with zero in 2007 and growing to approximately 99,000 total installations by October 2012. The counterfactual case assuming no rebates illustrates the large effect of the CSI on installations. Here, the overall growth in installations is much more modest, reaching a maximum of approximately 46,000 installations by October 2012. This suggests the effect of CSI was quite large, resulting in nearly 53,000 additional installations or approximately 53 percent of total installations. On the other hand, our estimates suggest approximately 47 percent of installations would have occurred absent rebates. In these cases, the CSI creates rents for inframarginal adopters. Using average rebate rates, these rents amount to about $\$ 121$ million out of approximately $\$ 440$ million in total rebates awarded 39

As discussed previously, these estimates and the calculations below exclude anticipatory effects or inter-temporal shifting of adoptions. Understanding short-run inter-temporal substitution is important for isolating the effect of rebate changes on adoptions. However, in the context of evaluating the overall impacts of the CSI this behavior is arguably less important than in the automobile policies studied by Sallee (2011) and Mian and Sufi (2012). Here, as argued in Section 4 we believe these effects are relatively short-lived. Adoptions shifted forward in time to take advantage of higher rebates are in a sense borrowed from a later time period and would have still occurred under the program, albeit several weeks later. Therefore, we ignore these effects when calculating the overall impacts of the CSI.

\footnotetext{
${ }^{39}$ Rents to inframarginal installations are calculated separately for each month in our sample. Specifically, we multiply the average monthly rebate level times the predicted number of installations in the zero rebate scenario. We sum calculated rents over all months to obtain an estimate of the program total.
} 


\subsection{Emission and cost-effectiveness}

One of the main justifications for incentivizing solar is that additional PV capacity lowers emissions associated with electricity generation. We use the predictions above to estimate reductions in $\mathrm{CO}_{2}$ and NOx emissions due to the CSI. To do this we assume none of the additional installations under the CSI would have occurred otherwise at some point in the future. That is to say, rebates create new adopters and don't simply result in the temporal shifting of future adoptions to the present. This assumption provides an upper bound on the environmental benefit of the CSI. For simplicity, we assume PV systems have a 20-year system life and ignore discounting 40 We assume a PV capacity factor of 0.18 and use two scenarios for the emissions of electricity generation displaced by solar installations ${ }^{41}$ In the first scenario we use average $\mathrm{CO}_{2}$ and $\mathrm{NOx}$ emissions rates for electricity generation. In the second scenario, we note that the solar generation profile is more likely to coincide with periods of peak electricity demand (Borenstein, 2008). We also use two sources for average and marginal emissions rates. Graff Zivin, Kotchen, and Mansur (2013) derive emission rates for the Western interconnection (WECC) using the US EPA's continuous emissions monitoring data for fossil-fuel electricity generating plants. To approximate the peak period, we average the Graff Zivin, Kotchen, and Mansur (2013) estimates over the period from 10am to 4pm ${ }^{42}$ Second, because WECC as a whole may be dirtier than California, we use California average emissions rates from eGRID (2009). We approximate peak emissions using annual "non-baseload" emissions rates.

Results of these calculations are summarized in Table 10. Under the CSI total solar capacity increases by approximately $240 \mathrm{MW}$. At the average emissions rate total emissions savings are approximately 2.73 $\mathrm{MMT} \mathrm{CO}_{2}$ using the WECC rate and $2.89 \mathrm{MMT} \mathrm{CO}_{2}$ using the California average. Assuming solar displaces primarily peak generation, the estimated $\mathrm{CO}_{2}$ emissions savings range from 2.89 MMT to 3.39 MMT. For NOx, the total estimated emissions savings over 20 years range from 1,096 to 1,712 MT depending on our assumption about the emissions rate of generation

\footnotetext{
${ }^{40}$ The assumption of zero discounting weighs equally system costs, incentives and benefits that accrue over many years of operation and treats equally carbon emissions reductions today and at the end of the system's life. Overall these assumptions are intentionally "generous" to the program in order to estimate an upper bound on the environmental benefits of the CSI and a lower bound on program costs.

${ }^{41} \mathrm{We}$ follow PG\&E in assuming an 18 percent capacity factor for PV systems http://www.pge.com/about/environment/calculator/assumptions.shtml. The capacity factor reflects average solar conditions throughout the year including hours of daylight, cloud cover and sun angle.

${ }^{42}$ Specifically, for $\mathrm{CO}_{2}$ we use average and peak rates of 0.36 and $0.38 \mathrm{MT}$ per MWh (WECC) and 0.30 and 0.45 MT per MWh (California). For NOx we use average and peak rates of 0.50 and $0.42 \mathrm{lb}$. per MWh (WECC) and 0.42 and $0.32 \mathrm{lb}$. per MWh (California).
} 
displaced by solar. To get a sense for the size of these emissions reductions, the $240 \mathrm{MW}$ of solar electricity capacity times the assumed capacity factor translates into approximately $40 \mathrm{MW}$ in effective capacity. The emissions rates we use here closely represent natural gas generators in California. Since gas fired plants in California range in size from several MW to several hundred MW, with median size of about $20 \mathrm{MW}$, these emissions reductions are comparable to removing a small to mid-sized gas plant. Arguably, these savings are modest but still non-trivial.

In terms of costs, a common measure of cost-effectiveness is program cost. Here we calculate program costs as total subsidy payments divided by total new electricity generation or carbon abatement. Program cost is a useful metric for comparing the direct costs of the CSI with other energy efficiency measures. Ranking programs by cost may allow regulators to do more with a fixed budget or achieve energy efficiency goals at lower cost. As such, this information is valuable to policy makers. However, this approach misses other important benefits of installing solar such as warm glow. Program cost also includes transfers to households that would have adopted solar absent rebates and excludes inefficiency from installations where marginal costs exceed marginal benefits. Here we focus on program costs because a welfare analysis in this context requires fairly restrictive assumptions.

Table 10 shows average program costs range from $\$ 152$ per MT to $\$ 161$ per $\mathrm{MT} \mathrm{CO}_{2}$ assuming WECC emissions and $\$ 130$ per MT to $\$ 196$ per $\mathrm{MT} \mathrm{CO}_{2}$ using California values. Subtracting transfers to installations that would have occurred absent rebates, program costs range from $\$ 94$ to $\$ 142$ per metric ton of carbon dioxide. We estimate program cost per kilowatt hour between $\$ 0.06$ and $\$ 0.04$ with and without transfers to inframarginal installations. These estimates are comparable to other energy efficiency programs (Gillingham, Newell, and Palmer, 2006; Chandra, Gulati, and Kandlikar, 2010, Allcott, 2011). To the extent policy makers are interested in increasing the number of installations, we estimate program costs per additional PV installation of approximately $\$ 8,400$.

\subsection{Limitations and qualifications}

Some qualifications of the results above are warranted. First, the calculations above can be thought of as a near-term analysis that holds fixed factors such as load, generation and the configuration of the electricity grid. Second, additional solar generation capacity may create other benefits such as reduced grid congestion, improvements in air quality and lower marginal generation costs. Here we 
abstract from these other potential benefits and instead focus on $\mathrm{CO}_{2}$ costs and generation to allow the reader to compare the CSI with other programs to reduce emissions ${ }^{43}$ Third, we ignore the possibility of peer effects such as those documented by Bollinger and Gillingham (2012), which may amplify or diminish the effect of rebates. Fourth and perhaps most important, some proponents of solar subsidies argue incentives are justified due to learning economies. Our counterfactual above assumes learning is negligible and therefore would underestimate the overall effect of the CSI on adoptions if learning effects are large.

While estimating the effect of learning is beyond the scope of this paper, we provide the following evidence our assumption of little learning is justified. First, learning implies a reduction in marginal costs as the industry streamlines production and installation processes. In terms of materials, over 50 percent of the final installed cost of a system is due to modules and other components for which prices have fallen considerably over the past decade ${ }^{44}$ However, the market for these components is global, and learning likely depends on total experience. California PV adoptions, particularly installations attributable to the CSI program, account for only a small percentage of the global PV market. As of 2012, approximately $100 \mathrm{GW}$ of PV capacity had been installed worldwide 45 of which about $0.5 \mathrm{GW}$ had been installed in our study area with only $0.3 \mathrm{GW}$ attributable to the CSI. Given that the CSI accounted for less than half a percent of the worldwide PV market, any learning effects of the CSI on lowering component costs are likely small. Moreover, recent studies by Nemet (2006) and Papineau (2006) find little evidence for learning in module costs.

Learning could also bring down labor and overhead costs associated with installation that account for approximately 25 percent of installed system cost.46 Baker et al. (2013) summarize recent estimates of learning-by-doing in the PV market. They find an association between cumulative installations and costs of approximately 20 percent. However, they note much of this effect may not be causal and the true contribution of learning is likely smaller. Given our finding that the

\footnotetext{
${ }^{43}$ For a more thorough discussion of these issues we refer the reader to Borenstein (2008) and Baker et al. (2013).

${ }^{44}$ The Solar Energy Industries Association reports a 60 percent decrease in average solar panel prices between 2011 and 2012, http://www.seia.org/research-resources/solar-industry-data

${ }^{45}$ According to the firm GlobalData, $98 \mathrm{GW}$ of PV capacity were installed worldwide as of 2012, http://www.pvmagazine.com/news/details/beitrag/330-gw-of-global-pv-capacity-predicted-by-2020_100010123/\#axzz2OKMJuYHI

${ }^{46}$ An NREL presentation by Woodhouse et al in 2011 reports an average price of $\$ 5.71$ per Watt for residential PV systems, of which $\$ 0.60$ is for electrical labor, $\$ 2.15$ for modules, $\$ 0.42$ for inverters, $\$ 0.46$ for BOS materials, $\$ 1.40$ for installer overhead, labor and profit, and the remainder for permitting taxes and miscellaneous. Assuming 10 percent profit for simplicity, this implies installer labor and overhead account for $\$ 0.83$. Together, all labor and overhead costs account for $\$ 1.43$ or 25 percent of total installed cost. See http://www.nrel.gov/docs/fy11osti/52311.pdf
} 
CSI roughly doubled adoptions during our study period, optimistically assuming an upper-bound learning rate of 20 percent implies a 20 percent decrease in labor and overhead costs. Since these costs contribute roughly 25 percent to final system prices, this translates to a 5 percent decrease in system price due to learning. In short, the incremental effect due to the CSI on prices appears small relative to the approximately 33 percent decrease in installed prices we observe over our study period.

\section{Conclusions}

The goal of this paper is to understand the effect of upfront subsidies on residential solar PV adoption. Because subsides are a common tool used by policy makers, quantifying consumer responses has implications for policies to promote solar and a variety of other green technologies. We explore this question in the context of the California Solar Initiative (CSI), a large and popular cash subsidy program aimed at increasing PV adoption. We focus on residential rebates under the CSI between 2007 and 2012. Across a variety of specifications we find a $\$ 0.10$ per Watt or approximately $\$ 400$ to $\$ 500$ increase in the rebate is associated with a 10 percent increase in the installation rate. Our preferred estimates suggest that without rebates nearly 53,000 or 53 percent fewer installations would have occurred during this period.

We explore the overall impacts of the program using a series of back of the envelope calculations. Of the approximately $\$ 440$ million in rebates paid during this period, approximately $\$ 121$ million are rents to households that would have adopted absent rebates. Because subsidies for green technologies are often motivated by energy or environmental goals, we estimate the overall increase in $\mathrm{PV}$ capacity and reduction in $\mathrm{CO}_{2}$ emissions under the program. We find solar capacity increases by approximately $240 \mathrm{MW}$ relative to a counterfactual assuming no rebates. Emissions of $\mathrm{CO}_{2}$ are between 2.25 million MT and 3.39 million MT lower due to the program. Similarly, we predict NOx emissions over 20 years fall between 1,096 and 1,712 MT. Based on these estimates, we calculate CSI program costs of $\$ 0.06$ per kilowatt hour and between $\$ 130$ and $\$ 196$ per metric ton of carbon dioxide.

In terms of program design, a key feature of the CSI is the declining schedule of rebates over time. This appears to have been motivated by the expectation that PV system prices would fall, 
potentially leading to a larger market for solar systems later in program. Our results in Table 7 suggest changes in rebates later in the sample have a larger effect on installation rates. Whether this is the effect of lower prices, third party installers, federal tax credits, stronger environmental preferences or more familiarity with solar technology remains an open question. Nevertheless, this design feature may have reduced the overall cost of the program by allowing CSI to pay lower rebates later in the program.

To explore this issue we compare total rebate payments under the CSI with a constant rebate designed to produce the same total number of installations. Using our three period model, the rebate required to achieve the same total number of installations is approximately $\$ 0.72$ per Watt. At this level, the overall expenditure on rebates would have been $\$ 329$ million compared with approximately $\$ 440$ under the actual program. In hindsight, the CSI may have achieved similar results with a constant rebate for over $\$ 100$ million less. That said, the declining rebate schedule did have the advantage of reducing year-to-year variation in rebate payments, which may have simplified planning and administration. Annual rebates awarded ranged from $\$ 60$ to $\$ 100$ million compared with $\$ 2$ to over $\$ 175$ in our constant rebate case. This is because fewer CSI installations took place during the early years when rebate rates were high and more occurred later when rebate rates were low. Of course, another potential advantage of the CSI declining rebate schedule over constant rebates is that more adoptions were encouraged early in the program. This feature may have helped support early installers through an initial period of high system prices and low demand.

The popularity of the CSI program could in part be due to benefits for inframarginal installations that would have occurred absent rebates. This feature appears to be a common characteristic of subsidy programs for green technologies. Chandra, Gulati, and Kandlikar (2010) and Boomhower and Davis (2014) similarly find that a large number of consumers of hybrid vehicles and energy efficient appliances would have purchased these goods absent rebates.

Overall, we find the CSI program had a large affect on adoption of residential PV systems in California. To the extent that increased production of renewable energy is a goal for policy makers, PV subsidies could play a role in reaching this goal. Our calculations suggest emissions reductions from new solar installations are modest and program costs of increasing adoption are comparable to other energy efficiency programs. 


\section{References}

Allcott, Hunt. 2011. "Social norms and energy conservation." Journal of Public Economics 95 (910):1082 - 1095.

Anderson, Soren T, Ryan Kellogg, and James M Sallee. 2013. "Journal of Environmental Economics and Management." Journal of Environmental Economics and Management 66:383-403.

Baker, Erin, Meredith Fowlie, Derek Lemoine, and Stanley S Reynolds. 2013. "The economics of solar electricity." Annual Review of Resource Economics 5 (1):387-426.

Barreca, Alan I., Jason M. Lindo, and Glen R. Waddell. 2011. "Heaping-induced Bias in RegressionDiscontinuity Designs." Working Paper 17408, National Bureau of Economic Research, Cambridge, MA.

Beresteanu, Arie and Shanjun Li. 2011. "Gasoline Prices, Government Support, and The Demand For Hybrid Vehicles In The United States." International Economic Review 52 (1):161-182.

Bollinger, Bryan and Kenneth Gillingham. 2012. "Peer effects in the diffusion of solar photovoltaic panels." Marketing Science 31 (6):900-912.

Boomhower, Judson and Lucas W. Davis. 2014. "A credible approach for measuring inframarginal participation in energy efficiency programs." Journal of Public Economics 113 (0):67 - 79.

Borenstein, Severin. 2008. "The Market Value and Cost of Solar Photovoltaic Electricity Production." Working Paper 176, Center for the Study of Energy Markets, University of California Energy Institute, Berkeley, CA.

Burr, Chrystie. 2012. "Subsidies, Tariffs and Investments in Solar Power Market." Working paper, University of Arizona, Tuscon, Department of Economics, Tuscon, AZ.

Cameron, A. Collin and Pravin K. Trivedi. 2005. Microeconometrics Methods and Applications. Cambridge University Press, New York.

Chandra, Ambarish, Sumeet Gulati, and Milind Kandlikar. 2010. "Green drivers or free riders? An analysis of tax rebates for hybrid vehicles." Journal of Environmental Economics and Management $60(2): 78-93$. 
CPUC. 2006. "California Public Utilities Commission Decision 06-12-033, December 14, 2006, Order Instituting Rulemaking Regarding Policies, Procedures and Rules for the California Solar Initiative, the Self-Generation Incentive Program and Other Distributed Generation Issues." URL http://docs.cpuc.ca.gov/PublishedDocs/WORD_PDF/FINAL_DECISION/63031.PDF. Accessed, April 7, 2013.

Dastrup, Samuel R, Joshua Graff Zivin, Dora L Costa, and Matthew E Kahn. 2012. "Understanding the Solar Home Price Premium: Electricity Generation and Green Social Status." European Economic Review 56 (5):961-973.

Deng, Yongheng, Zhiliang Li, and John M Quigley. 2012. "Economic returns to energy-efficient investments in the housing market: evidence from Singapore." Regional Science and Urban Economics $42(3): 506-515$.

eGRID, US EPA. 2009. "eGRID2012 Version 1.0 Year 2009 GHG Annual Output Emission Rates." URL http://www.epa.gov/cleanenergy/documents/egridzips/eGRID2012V1_ 0_year09_GHGOutputrates.pdf. Accessed, April 3, 2013.

Eichholtz, Piet, Nils Kok, and John M Quigley. 2013. "The economics of green building." Review of Economics and Statistics 95 (1):50-63.

Gallagher, Kelly Sims and Erich Muehlegger. 2011. "Giving green to get green? Incentives and consumer adoption of hybrid vehicle technology." Journal of Environmental Economics and Management $61(1): 1-15$.

Gillingham, Kenneth, Richard Newell, and Karen Palmer. 2006. "Energy efficiency policies: a retrospective examination." Annu. Rev. Environ. Resour. 31:161-192.

Glaeser, Edward L and Matthew E Kahn. 2010. "The greenness of cities: carbon dioxide emissions and urban development." Journal of Urban Economics 67 (3):404-418.

Gowrisankaran, Gautam, Stanley S Reynolds, and Mario Samano. 2013. "Intermittency and the value of renewable energy." Working Paper 17086, National Bureau of Economic Research, Cambridge, MA. 
Graff Zivin, Joshua, Matthew J. Kotchen, and Erin T. Mansur. 2013. "Spatial and Temporal Heterogeneity of Marginal Emissions: Implications for Electric Cars and Other Electricity-Shifting Policies." Working paper, Dartmouth College, Hanover, NH.

Ito, Koichiro. 2014. "Do consumers respond to marginal or average price? Evidence from nonlinear electricity pricing." American Economic Review 104 (2):537-563.

Kahn, Matthew E and Nils Kok. 2013. "The Capitalization of Green Labels in the California Housing Market." Regional Science and Urban Economics .

Mian, Atif and Amir Sufi. 2012. "The Effects of Fiscal Stimulus: Evidence from the 2009 Cash for Clunkers Program." The Quarterly Journal of Economics 127 (3):1107-1142.

Millard-Ball, Adam. 2012. "Do city climate plans reduce emissions?" Journal of Urban Economics $71(3): 289-311$.

Nemet, Gregory F. 2006. "Beyond the learning curve: factors influencing cost reductions in photovoltaics." Energy Policy 34 (17):3218-3232.

Papineau, Maya. 2006. "An economic perspective on experience curves and dynamic economies in renewable energy technologies." Energy Policy 34 (4):422-432.

Sallee, James M. 2011. "The Surprising Incidence of Tax Credits for the Toyota Prius." American Economic Journal: Economic Policy 3 (2):189-219.

Van Benthem, Arthur, Kenneth Gillingham, and James Sweeney. 2008. "Learning-by-doing and the optimal solar policy in California." Energy Journal 29 (3):131. 


\section{$9 \quad$ Figures}

Figure 1: Spatial intensity of PV installations calculated as the total number of CSI residential PV installations in a zip code divided by population density.

PV Installs./Pop. Density (Persons/sq. mi.)

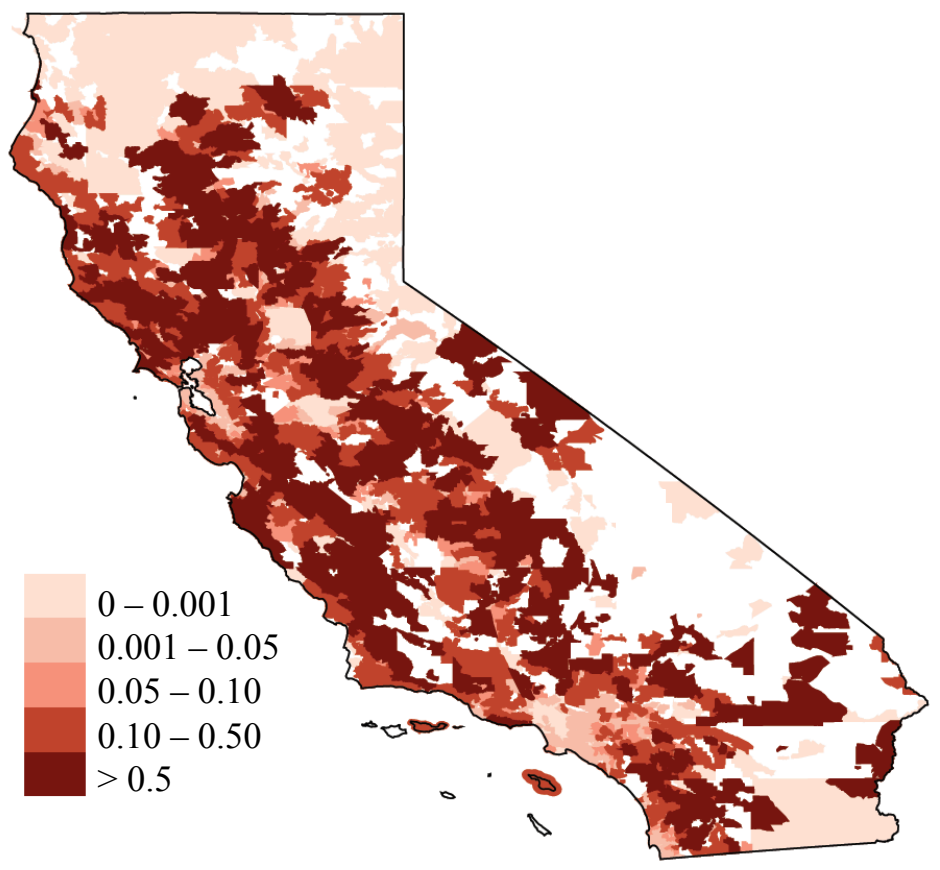


Figure 2: Average rebates, system prices and installations for Pacific Gas and Electric (PG\&E), Southern California Edison (SCE) and San Diego Gas and Electric (SDG\&E).

(a) PG\&E

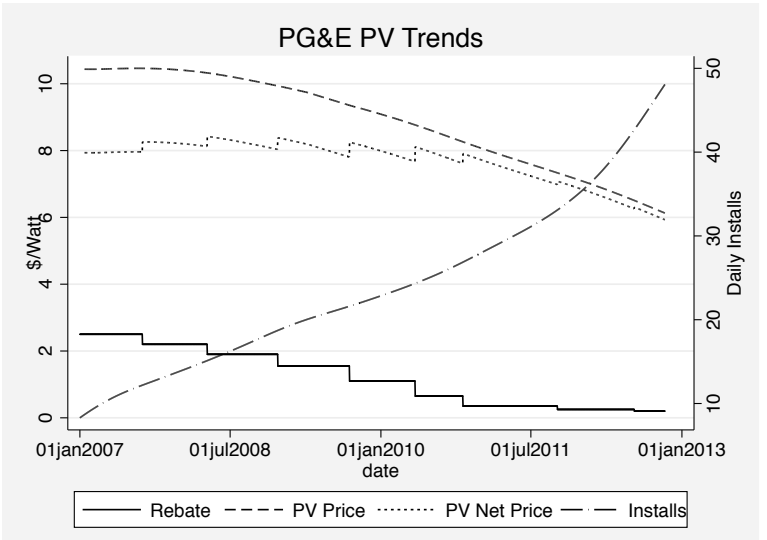

(b) SCE

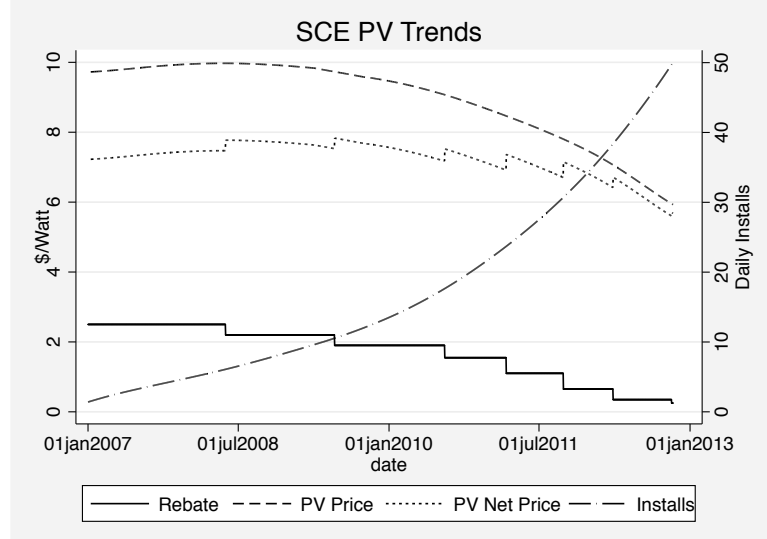

(c) SDG\&E

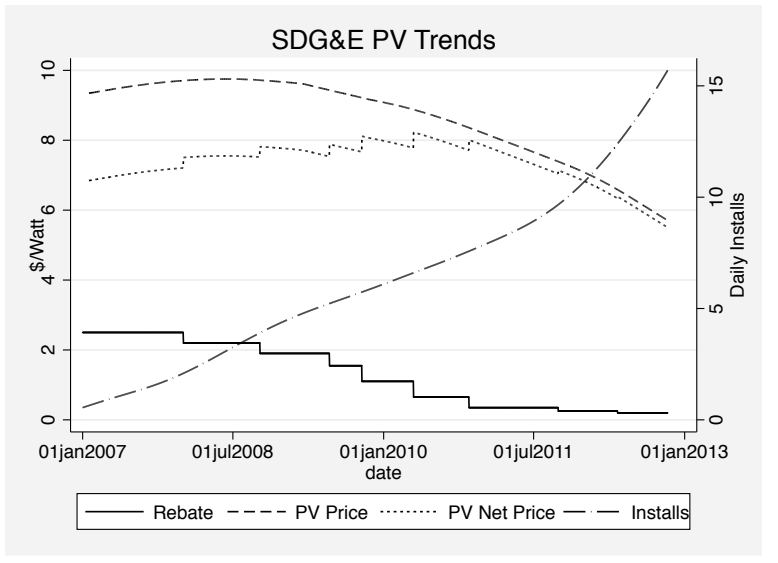


Figure 3: Total installations per day for Pacific Gas and Electric (PG\&E), Southern California Edison (SCE) and San Diego Gas and Electric (SDG\&E).

(a) PG\&E

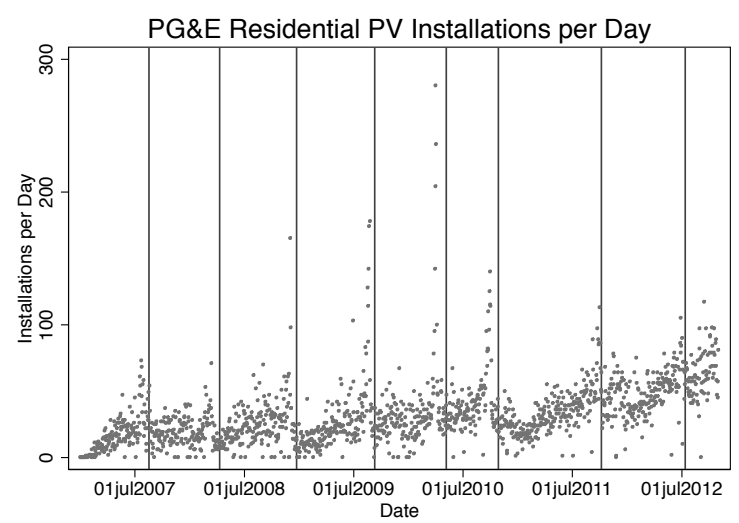

(b) SCE

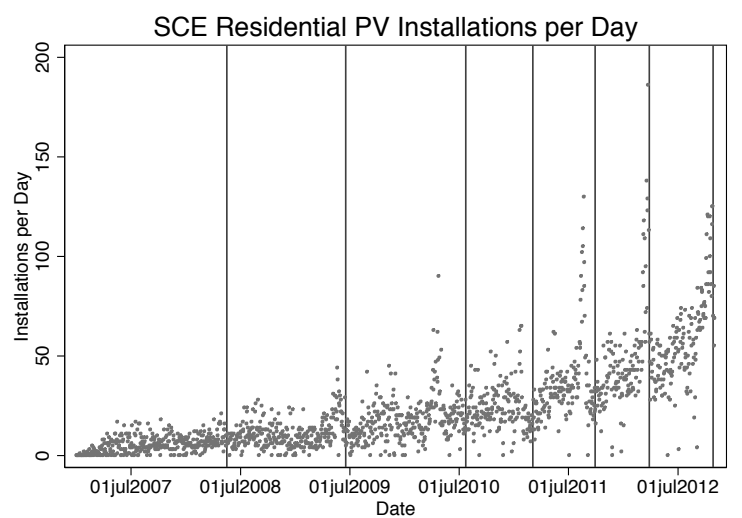

(c) SDG\&E

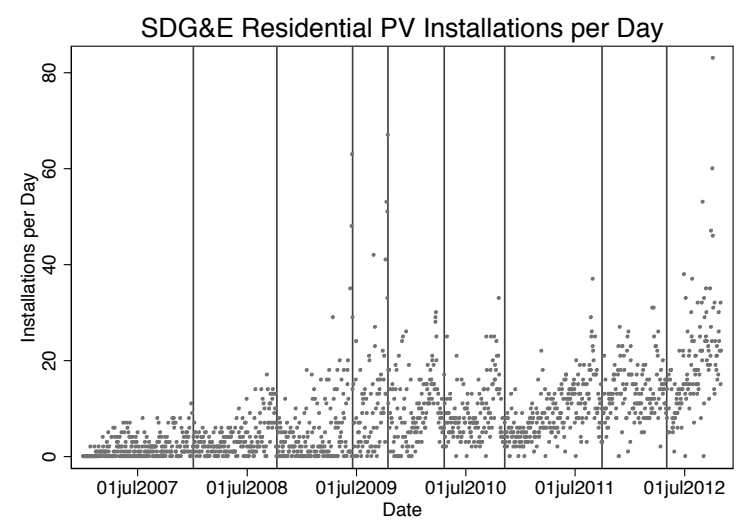


Figure 4: Map of PG\&E, SCE and SDG\&E territories and the PG\&E-SCE boundary region. Zip codes included in the 20-mile buffer sample are darkly shaded in the righthand figure.
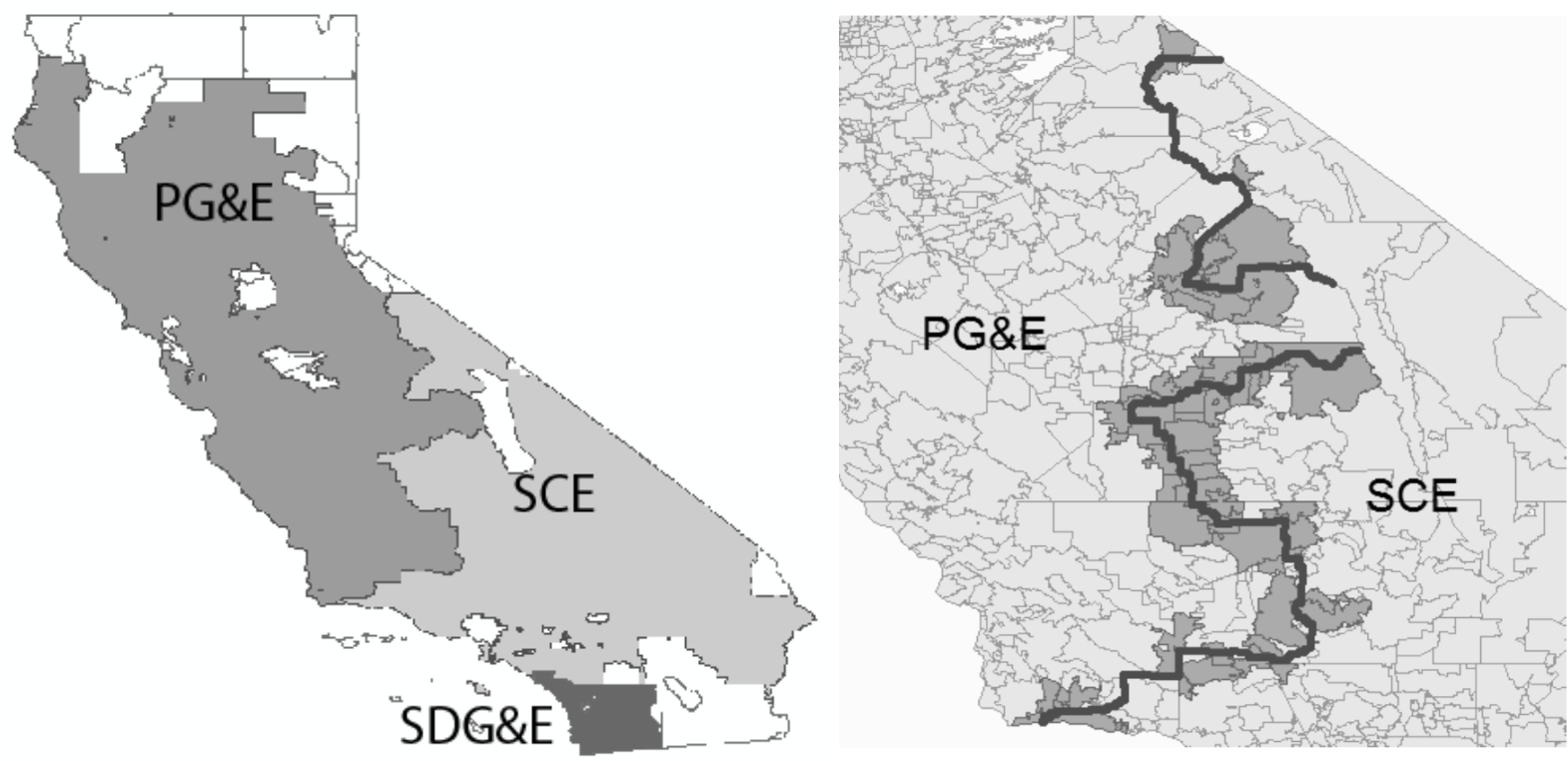
Figure 5: Predicted total PV installations and counterfactual installations assuming no CSI program rebates.

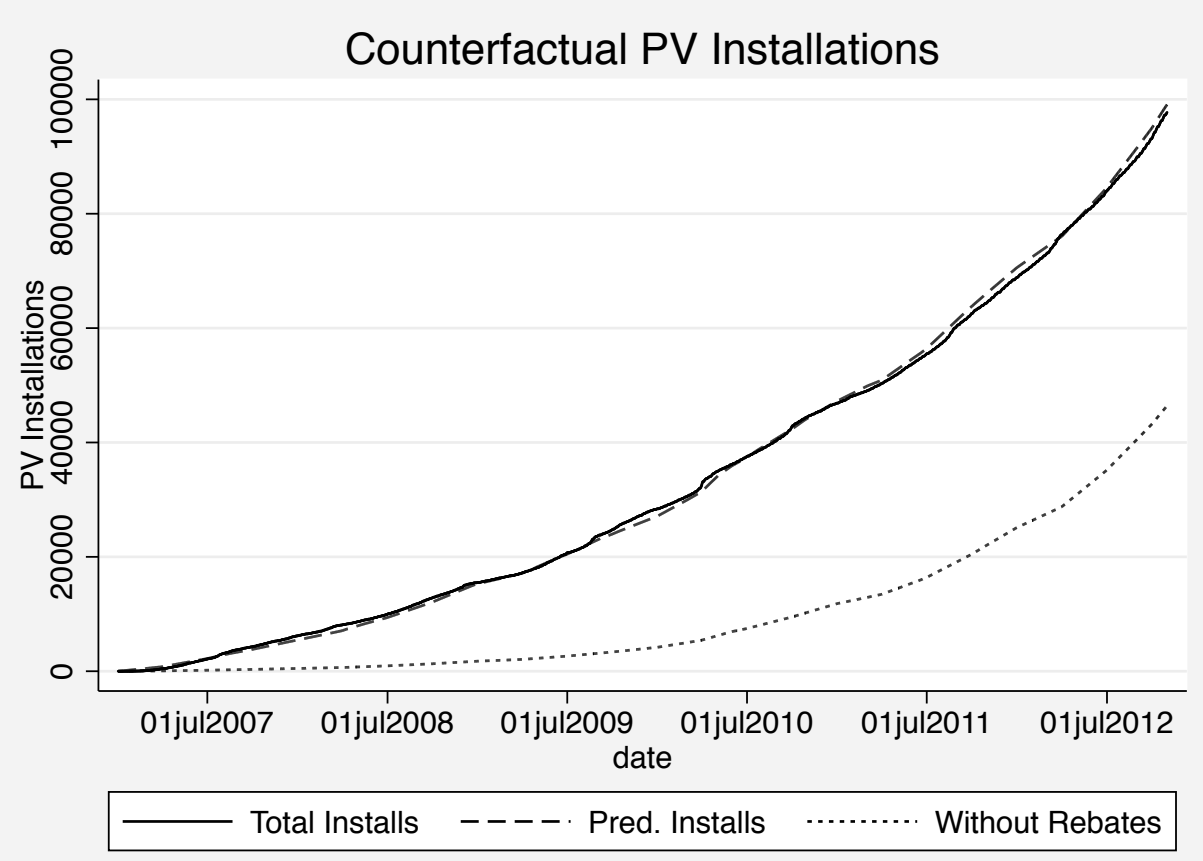




\section{Tables}

Table 1: CSI rebate rate schedule for EPBB program by utility.

\begin{tabular}{cccccc}
\hline Step & $\begin{array}{c}\text { Rebate Rate } \\
(\$ / \mathrm{W})\end{array}$ & $\begin{array}{c}\text { Total Capacity } \\
(\mathrm{MW})\end{array}$ & $\begin{array}{c}\text { PG\&E Capacity } \\
(\mathrm{MW})\end{array}$ & $\begin{array}{c}\text { SCE Capacity } \\
(\mathrm{MW})\end{array}$ & $\begin{array}{c}\text { SDG\&E Capacity } \\
(\mathrm{MW})\end{array}$ \\
\hline 1 & $\mathrm{n} / \mathrm{a}$ & 50 & 0.0 & 0.1 & 0.0 \\
2 & $\$ 2.50$ & 70 & 10.1 & 10.6 & 2.4 \\
3 & $\$ 2.20$ & 100 & 14.4 & 15.2 & 3.4 \\
4 & $\$ 1.90$ & 130 & 18.7 & 19.7 & 4.4 \\
5 & $\$ 1.55$ & 160 & 23.1 & 24.3 & 5.4 \\
6 & $\$ 1.10$ & 190 & 27.4 & 28.8 & 6.5 \\
7 & $\$ 0.65$ & 215 & 31.0 & 32.6 & 7.3 \\
8 & $\$ 0.35$ & 250 & 36.1 & 38.0 & 8.5 \\
9 & $\$ 0.25$ & 285 & 41.1 & 43.3 & 9.7 \\
10 & $\$ 0.20$ & 350 & 50.5 & 53.1 & 11.9 \\
\hline
\end{tabular}

Notes: Adapted from CSI Statewide Trigger Tracker at http://www.csi-trigger.com/ 
Table 2: Observable household characteristics by geographic region.

Differences in Zip Code Means of Observable Demographics and House Characteristics Across Utilities

\begin{tabular}{|c|c|c|c|c|c|c|c|c|}
\hline & & Population & \% White & HH Income & $\%$ Family & $\begin{array}{c}\text { \% Own. } \\
\text { Occ. }\end{array}$ & Rooms & Year Built \\
\hline \multicolumn{9}{|l|}{ full sample } \\
\hline & PG\&E & 35,271 & 0.63 & 54,384 & 0.71 & 0.59 & 5.08 & 1970.4 \\
\hline & SCE & 45,607 & 0.57 & 49,112 & 0.76 & 0.57 & 4.86 & 1968.8 \\
\hline & Difference & $-10,336 * * *$ & $0.07^{* * *}$ & $5,273 * * *$ & $-0.05^{* * *}$ & 0.02 & $0.21^{* * *}$ & 1.56 \\
\hline \multicolumn{9}{|l|}{$40 \mathrm{mi}$. buffer } \\
\hline & PG\&E & 34,789 & 0.61 & 38,060 & 0.78 & 0.57 & 4.99 & 1973.5 \\
\hline & SCE & 28,750 & 0.66 & 40,671 & 0.73 & 0.55 & 4.81 & 1956.4 \\
\hline & Difference & $6,039 *$ & $-0.06^{*}$ & $-2,611$ & $0.05^{* * *}$ & 0.03 & 0.18 & 17.10 \\
\hline \multicolumn{9}{|l|}{$20 \mathrm{mi}$. buffer } \\
\hline & PG\&E & 31,496 & 0.61 & 36,509 & 0.77 & 0.55 & 4.85 & 1973.5 \\
\hline & SCE & 33,382 & 0.66 & 39,437 & 0.75 & 0.57 & 4.94 & 1972.8 \\
\hline & Difference & $-1,886$ & $-0.05^{*}$ & $-2,927$ & $0.02 *$ & -0.02 & -0.09 & 0.70 \\
\hline
\end{tabular}

Notes: Reported observables are populated weighted means of zip code average values. Test statistics for differences in means are from a populated weighted regression where standard errors are clustered the zipcode level. ${ }^{* * *}, * *$ and ${ }^{*}$ denote significance at the 1 percent, 5 percent and 10 percent levels respectively. 
Table 3: Summary statistics for the full sample and the 20-mile corridor.

\begin{tabular}{|c|c|c|c|c|}
\hline & Mean & Std. Dev. & Max. & Min. \\
\hline & & Full Sample & & \\
\hline \multicolumn{5}{|l|}{ PG\&E } \\
\hline total rebate $(\$)$ & 4,002 & 4,950 & 137,895 & 53 \\
\hline rebate rate $(\$ / W)$ & 1.21 & 0.82 & 2.50 & 0.20 \\
\hline total system cost (\$) & 36,474 & 24,925 & $1,028,017$ & 0 \\
\hline CSI rating $(\mathbf{k W})$ & 4.46 & 2.82 & 71.55 & 0.27 \\
\hline installation rate (num./day) & 23.40 & 24.57 & 280.00 & 0.00 \\
\hline total installations & 49,866 & & & \\
\hline \multicolumn{5}{|l|}{ SCE } \\
\hline total rebate $(\$)$ & 5,291 & 5,069 & 137,216 & 252 \\
\hline rebate rate $(\$ / W)$ & 1.72 & 0.72 & 2.50 & 0.25 \\
\hline total system cost (\$) & 37,377 & 21,109 & 483,784 & 0 \\
\hline CSI rating $(\mathbf{k W})$ & 4.77 & 2.67 & 54.88 & 0.72 \\
\hline installation rate (num./day) & 16.39 & 21.11 & 186.00 & 0.00 \\
\hline total installations & 34,925 & & & \\
\hline \multicolumn{5}{|l|}{ SDG\&E } \\
\hline total rebate $(\$)$ & 3,612 & 4,382 & 106,240 & 201 \\
\hline rebate rate $(\$ / W)$ & 1.28 & 0.89 & 2.50 & 0.20 \\
\hline total system cost (\$) & 35,864 & 20,256 & 396,560 & 1,400 \\
\hline CSI rating $(\mathbf{k W})$ & 4.72 & 2.74 & 48.29 & 0.80 \\
\hline installation rate (num./day) & 6.07 & 7.92 & 83.00 & 0.00 \\
\hline total installations & 12,939 & & & \\
\hline & & 0 -mile corrid & & \\
\hline \multicolumn{5}{|l|}{ PG\&E } \\
\hline total rebate $(\$)$ & 4,572 & 4,925 & 40,710 & 349 \\
\hline rebate rate $(\$ / W)$ & 1.21 & 0.82 & 2.50 & 0.20 \\
\hline total system cost (\$) & 42,990 & 23,211 & 191,787 & 4,898 \\
\hline CSI rating $(\mathrm{kW})$ & 5.68 & 2.94 & 28.51 & 1.02 \\
\hline installation rate (num./day) & 0.56 & 1.03 & 8.00 & 0.00 \\
\hline zip code install. rate (num./day) & 0.01 & 0.13 & 4.00 & 0.00 \\
\hline total installations & 1,192 & & & \\
\hline \multicolumn{5}{|l|}{ SCE } \\
\hline total rebate $(\$)$ & 6,175 & 5,537 & 63,954 & 383 \\
\hline rebate rate $(\$ / W)$ & 1.72 & 0.72 & 2.50 & 0.25 \\
\hline total system cost (\$) & 39,224 & 21,844 & 226,781 & 3,000 \\
\hline CSI rating $(\mathrm{kW})$ & 5.19 & 2.79 & 34.14 & 0.97 \\
\hline installation rate (num./day) & 0.85 & 1.40 & 11.00 & 0.00 \\
\hline zip code install. rate (num./day) & 0.03 & 0.19 & 4.00 & 0.00 \\
\hline total installations & 1,804 & & & \\
\hline
\end{tabular}


Table 4: Effect of California Solar Initiative (CSI) rebate rates on the daily PV installation rate near the PG\&E and SCE boundary.

Models for Average Daily Installation Rates in 20 Mile Region

\begin{tabular}{|c|c|c|c|}
\hline & $\begin{array}{l}\text { (1) } \\
\text { OLS }\end{array}$ & $\begin{array}{c}\text { (2) } \\
\text { Poisson }\end{array}$ & $\begin{array}{c}\text { (3) } \\
\text { Neg. Binomial }\end{array}$ \\
\hline Rebate rate $(\$ / W)$ & $\begin{array}{l}0.051 * * * \\
(0.0040)\end{array}$ & $\begin{array}{l}0.951 * * \\
(0.4210)\end{array}$ & $\begin{array}{l}0.963 * * \\
(0.4250)\end{array}$ \\
\hline $\begin{array}{l}\text { Confidence interval }(95 \%) \\
\% \text { change in install rate }\end{array}$ & $\begin{array}{c}{[0.044,0.059]} \\
19.1 \%\end{array}$ & $\begin{array}{c}{[0.126,1.775]} \\
10.0 \%\end{array}$ & $\begin{array}{c}{[0.130,1.795]} \\
10.1 \%\end{array}$ \\
\hline Tier $3(\$ / k W h)$ & $\begin{array}{c}-0.127 * * * \\
(0.0140)\end{array}$ & $\begin{array}{l}6.540 * * * \\
(1.9460)\end{array}$ & $\begin{array}{l}7.069 * * * \\
(2.2000)\end{array}$ \\
\hline Tier $4(\$ / k W h)$ & $\begin{array}{l}0.130 * * \\
(0.0560)\end{array}$ & $\begin{array}{l}-10.544 \\
(6.9720)\end{array}$ & $\begin{array}{l}-10.709 \\
(7.3530)\end{array}$ \\
\hline Tier $5(\$ / k W h)$ & $\begin{array}{c}0.126 \\
(0.0850)\end{array}$ & $\begin{array}{l}11.276 * * \\
(4.3950)\end{array}$ & $\begin{array}{l}11.350 * * \\
(4.6970)\end{array}$ \\
\hline In(Population) & & $\begin{array}{l}0.981 * * * \\
(0.0580)\end{array}$ & $\begin{array}{l}0.989 * * * \\
(0.0680)\end{array}$ \\
\hline $\begin{array}{l}\text { Quarter Effects } \\
\text { Utility by Year Effects } \\
\text { Observations }\end{array}$ & $\begin{array}{c}\begin{array}{c}\text { Yes } \\
\text { Yes }\end{array} \\
122294\end{array}$ & $\begin{array}{c}\text { Yes } \\
\text { Yes } \\
122294\end{array}$ & $\begin{array}{c}\text { Yes } \\
\text { Yes } \\
122294\end{array}$ \\
\hline \multicolumn{4}{|c|}{$\begin{array}{l}\text { Notes: Dependent variable in OLS model is total daily PV installations per } 10,000 \\
\text { persons population by utility and zip code for zip codes within } 20 \text { mile buffer. } \\
\text { Dependent variables for Poisson and Negative Binomial models are total installations } \\
\text { per day by utility and zip code for zip codes within } 20 \text { mile buffer. Percentage change } \\
\text { in installation rate calculated for a } \$ 0.10 \text { increase in the rebate rate at the mean } \\
\text { values of independent variables. Standard errors clustered at the utility level. All } \\
\text { models drop observations } 4 \text { weeks before and } 4 \text { weeks after each rebate change. } \\
* * *, * * \text { and } * \text { denote significance at the } 1 \text { percent, } 5 \text { percent and } 10 \text { percent levels. }\end{array}$} \\
\hline
\end{tabular}




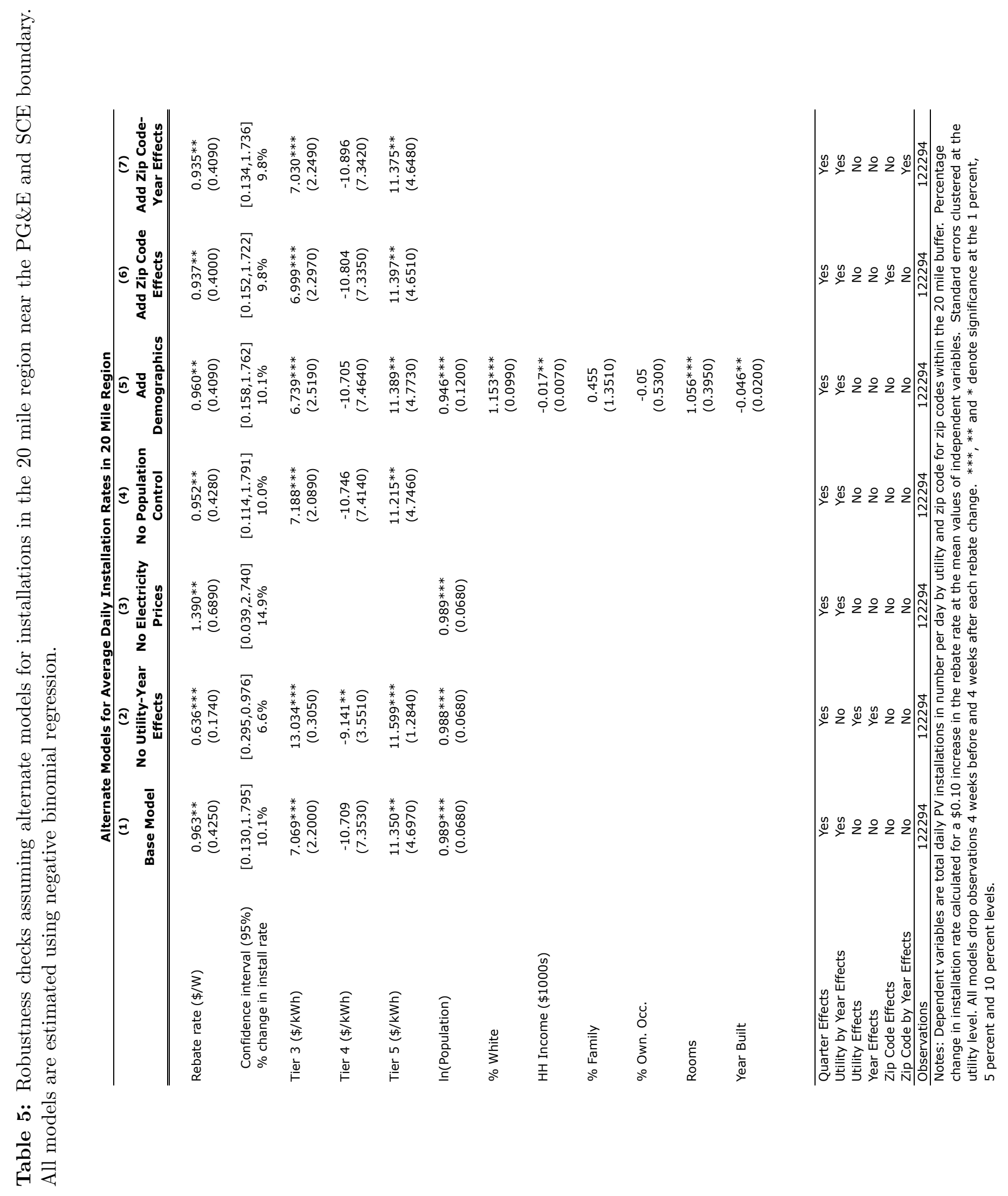


Table 6: Robustness to excluding different periods near rebate step changes for installations in the 20 mile region near the PG\&E and SCE boundary. All models are estimated using negative binomial regression.

Robustness to Excluding Observations Near Rebate Change Dates

\begin{tabular}{|c|c|c|c|c|c|}
\hline & $\begin{array}{c}\text { (1) } \\
\text { All Weeks }\end{array}$ & $\begin{array}{c}\text { (2) } \\
2 \text { wk. }\end{array}$ & $\begin{array}{c}\text { (3) } \\
\text { Base Model }\end{array}$ & $\begin{array}{c}(4) \\
8 \text { wk. }\end{array}$ & $\begin{array}{c}(5) \\
12 \text { wk. }\end{array}$ \\
\hline Rebate rate $(\$ / \mathrm{W})$ & $\begin{array}{c}1.084 * \\
(0.6030)\end{array}$ & $\begin{array}{l}1.024 * * \\
(0.5220)\end{array}$ & $\begin{array}{l}0.963 * * \\
(0.4250)\end{array}$ & $\begin{array}{l}0.676 * * \\
(0.2950)\end{array}$ & $\begin{array}{l}0.942 * * \\
(0.4130)\end{array}$ \\
\hline $\begin{array}{l}\text { Confidence interval }(95 \%) \\
\% \text { change in install rate }\end{array}$ & $\begin{array}{c}{[-0.098,2.265]} \\
11.4 \%\end{array}$ & $\begin{array}{c}{[0.001,2.046]} \\
10.8 \%\end{array}$ & $\begin{array}{c}{[0.130,1.795]} \\
10.1 \%\end{array}$ & $\begin{array}{c}{[0.098,1.253]} \\
7.0 \%\end{array}$ & $\begin{array}{c}{[0.132,1.752]} \\
9.9 \%\end{array}$ \\
\hline Tier $3(\$ / k W h)$ & $\begin{array}{l}9.387 * * * \\
(3.2530)\end{array}$ & $\begin{array}{l}7.447 * * * \\
(2.4550)\end{array}$ & $\begin{array}{l}7.069 * * * \\
(2.2000)\end{array}$ & $\begin{array}{c}10.473 \\
(8.5990)\end{array}$ & $\begin{array}{l}14.086 * * \\
(6.6040)\end{array}$ \\
\hline Tier 4 ( $\$ / \mathrm{kWh})$ & $\begin{array}{c}-8.552 \\
(8.3120)\end{array}$ & $\begin{array}{l}-7.736 \\
(8.1100)\end{array}$ & $\begin{array}{l}-10.709 \\
(7.3530)\end{array}$ & $\begin{array}{l}-12.597 \\
(9.7820)\end{array}$ & $\begin{array}{l}-22.473 \\
(26.5760)\end{array}$ \\
\hline Tier $5(\$ / k W h)$ & $\begin{array}{c}7.11 \\
(5.3700)\end{array}$ & $\begin{array}{c}8.515^{*} \\
(5.0890)\end{array}$ & $\begin{array}{l}11.350 * * \\
(4.6970)\end{array}$ & $\begin{array}{c}10.458 \\
(6.7970)\end{array}$ & $\begin{array}{c}20.619 \\
(24.1320)\end{array}$ \\
\hline In(Population) & $\begin{array}{l}0.996 * * * \\
(0.0660)\end{array}$ & $\begin{array}{l}0.990 * * * \\
(0.0650)\end{array}$ & $\begin{array}{l}0.989 * * * \\
(0.0680)\end{array}$ & $\begin{array}{c}0.995 * * * \\
(0.0630)\end{array}$ & $\begin{array}{c}0.984 * * * \\
(0.0550)\end{array}$ \\
\hline $\begin{array}{l}\text { Quarter Effects } \\
\text { Utility by Year Effects }\end{array}$ & $\begin{array}{l}\text { Yes } \\
\text { Yes }\end{array}$ & $\begin{array}{l}\text { Yes } \\
\text { Yes }\end{array}$ & $\begin{array}{l}\text { Yes } \\
\text { Yes }\end{array}$ & $\begin{array}{l}\text { Yes } \\
\text { Yes }\end{array}$ & $\begin{array}{l}\text { Yes } \\
\text { Yes }\end{array}$ \\
\hline Observations & 151301 & 136980 & 122294 & 92922 & 63550 \\
\hline \multicolumn{6}{|c|}{$\begin{array}{l}\text { Notes: Dependent variables are the total daily PV installation rates in number per day by utility and zip code for zip } \\
\text { codes within the } 20 \text { mile buffer. The base model drops observations } 4 \text { weeks before and } 4 \text { weeks after each rebate } \\
\text { change. Model } 1 \text { includes all observations around rebate changes. " } 2 \text { week," " } 8 \text { week," and "12 week" models drop } \\
\text { observations within } 2,8 \text { and } 12 \text { weeks of each rebate change. Percentage change in installation rate calculated for a } \\
\$ 0.10 \text { increase in the rebate rate at the mean values of independent variables. Standard errors clustered at the utility } \\
\text { level. } * * *, * * \text { and } * \text { denote significance at the } 1 \text { percent, } 5 \text { percent and } 10 \text { percent levels. }\end{array}$} \\
\hline
\end{tabular}


Table 7: Effect of California Solar Initiative (CSI) rebate rates on the daily PV installation rate near the PG\&E and SCE boundary during different sample periods. All models are estimated using negative binomial regression.

Average Daily Installation Rates in 20 Mile Region by Period

\begin{tabular}{|c|c|c|c|}
\hline & 2007-2008 & 2009-2010 & 2011-2012 \\
\hline Rebate rate $(\$ / \mathrm{W})$ & $\begin{array}{c}1.816 * * * \\
(0.6490)\end{array}$ & $\begin{array}{c}1.292 * * * \\
(0.0290)\end{array}$ & $\begin{array}{c}0.745^{* * *} \\
(0.2730)\end{array}$ \\
\hline Confidence interval (95\%) & {$[0.544,3.087]$} & {$[1.235,1.350]$} & {$[0.211,1.279]$} \\
\hline$\%$ change in install rate & $19.9 \%$ & $13.8 \%$ & $7.7 \%$ \\
\hline Level Change in install rate & 0.0019 & 0.0023 & 0.0027 \\
\hline Quarter Effects & Yes & Yes & Yes \\
\hline Utility by Year Effects & Yes & Yes & Yes \\
\hline Observations & 122294 & 122294 & 122294 \\
\hline \multicolumn{4}{|c|}{$\begin{array}{l}\text { Notes: Dependent variables are the total daily PV installation rates in number per } \\
\text { day by utility and zip code for zip codes within } 20 \text { mile buffer. Percentage change in } \\
\text { installation rate calculated for a } \$ 0.10 \text { increase in the rebate rate. Standard errors } \\
\text { clustered at the utility level. We drop observations } 4 \text { weeks before and } 4 \text { weeks after } \\
\text { each rebate change. } * * *, * * \text { and } * \text { denote significance at the } 1 \text { percent, } 5 \text { percent } \\
\text { and } 10 \text { percent levels. }\end{array}$} \\
\hline
\end{tabular}




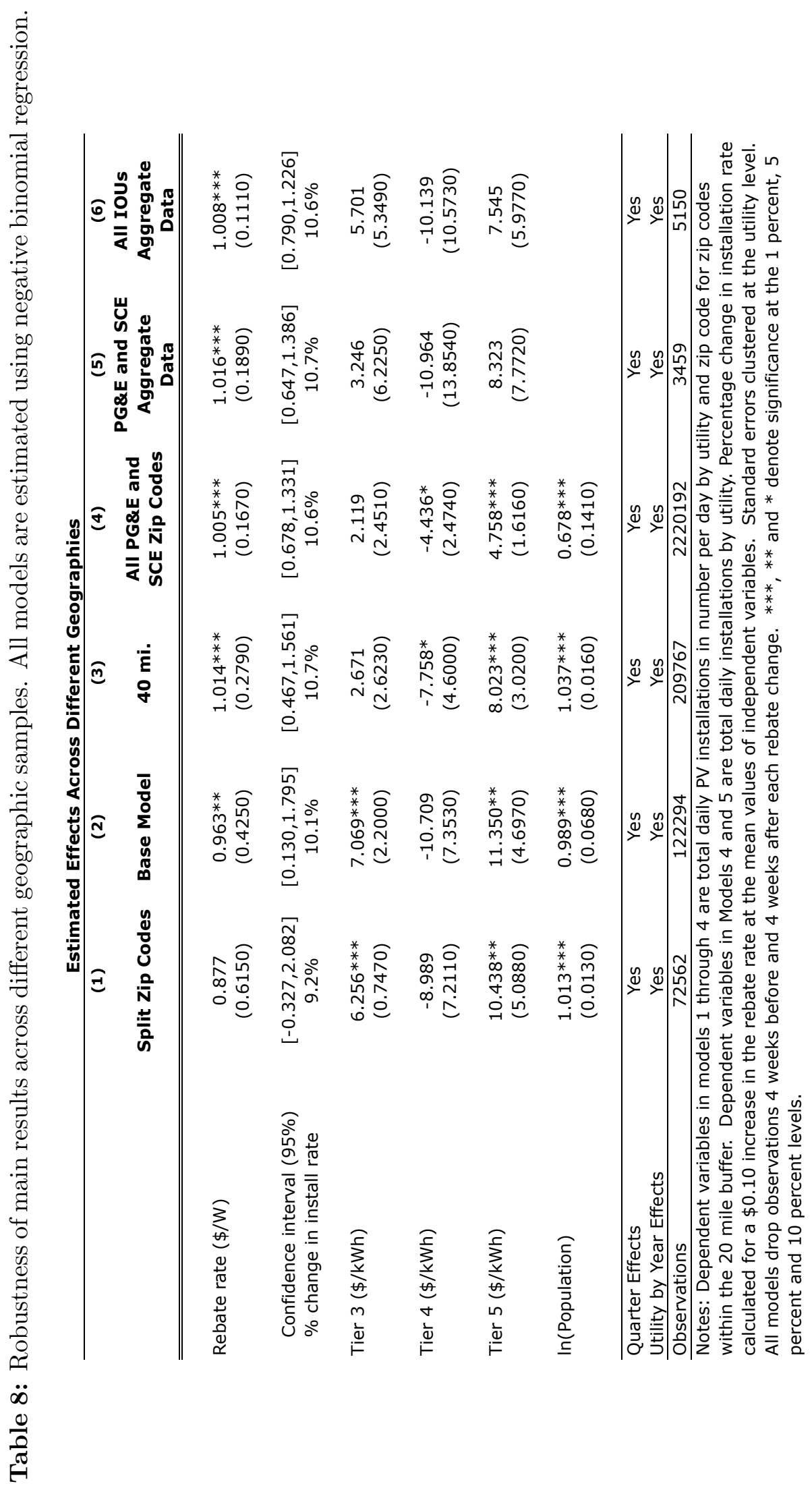


Table 9: Effect of rebates on installation rates by utility. All models are estimated using negative binomial regression.

Effect of Rebates on Average Daily Installation Rates by Utility

\begin{tabular}{|c|c|c|c|}
\hline & PG\&E & SCE & SDG\&E \\
\hline Rebate rate $(\$ / \mathrm{W})$ & $\begin{array}{c}0.971 * * * \\
(0.3240)\end{array}$ & $\begin{array}{c}1.026 * * * \\
(0.0690)\end{array}$ & $\begin{array}{c}1.008 * * * \\
(0.0910)\end{array}$ \\
\hline $\begin{array}{l}\text { Confidence interval }(95 \%) \\
\% \text { change in install rate }\end{array}$ & $\begin{array}{c}{[0.336,1.606]} \\
10.2 \%\end{array}$ & $\begin{array}{c}{[0.892,1.161]} \\
10.8 \%\end{array}$ & $\begin{array}{c}{[0.830,1.186]} \\
10.6 \%\end{array}$ \\
\hline Quarter Effects & Yes & Yes & Yes \\
\hline Utility by Year Effects & Yes & Yes & Yes \\
\hline Observations & 5150 & 5150 & 5150 \\
\hline \multicolumn{4}{|c|}{$\begin{array}{l}\text { Notes: Dependent variables are the total daily PV installation rates in number per } \\
\text { day by utility for all zip codes within PG\&E, SCE and SDG\&E territories. Percentage } \\
\text { change in installation rate calculated for a } \$ 0.10 \text { increase in the rebate rate. We } \\
\text { drop observations } 4 \text { weeks before and } 4 \text { weeks after each rebate change. Standard } \\
\text { errors clustered at the utility level. } * * *, * * \text { and } * \text { denote significance at the } 1 \\
\text { percent, } 5 \text { percent and } 10 \text { percent levels. }\end{array}$} \\
\hline
\end{tabular}


Table 10: Installations, capacity, emissions and cost-effectiveness under the California Solar Initiative.

\section{Overall Impacts of the California Solar Initiative}

CSI Overall (All IOUs)

Total Installations 99,087

Intallations Without Rebates

Percentage Due to CSI 46,407 $53 \%$

Total Capacity (kW)

454,556

Capacity Without Rebates

215,854

Percentage Due to CSI

$53 \%$

Total Subsidy Payments (\$M)

$\$ \quad 440$

Rents to Inframarginal Install.

$\$ \quad 121$

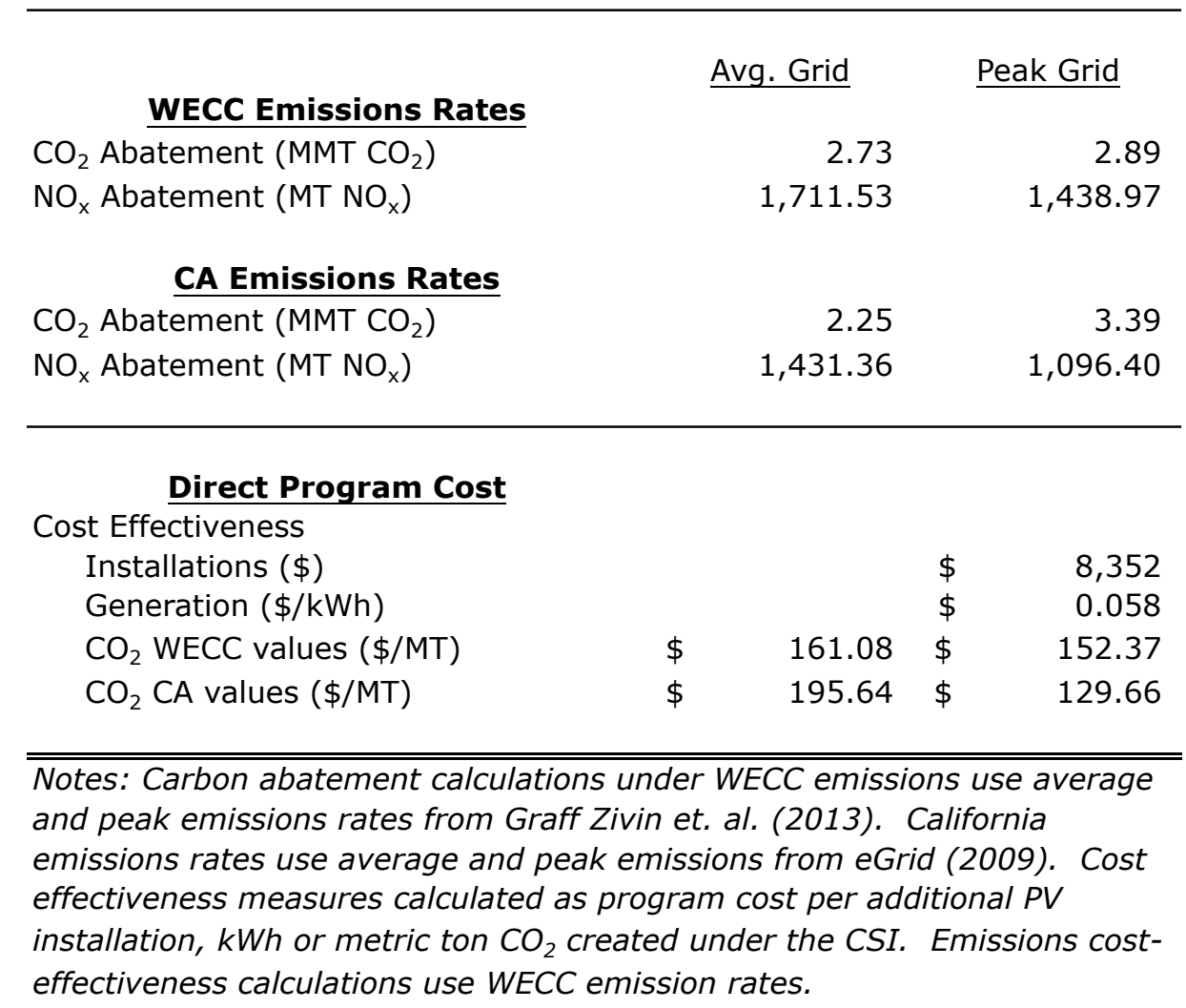

